\title{
Impact of RNA structure on ZFP36L2 interaction with luteinizing hormone receptor mRNA
}

\author{
CHRISTOPHER B. BALL, ${ }^{1,5}$ AMANDA C. SOLEM, ${ }^{2,6}$ RITA M. MEGANCK, ${ }^{3}$ ALAIN LAEDERACH, ${ }^{2,4}$ \\ and SILVIA B.V. RAMOS ${ }^{1}$ \\ ${ }^{1}$ Biochemistry and Biophysics Department, University of North Carolina, Chapel Hill, North Carolina 27599, USA \\ ${ }^{2}$ Biology Department, University of North Carolina, Chapel Hill, North Carolina 27599, USA \\ ${ }^{3}$ Curriculum in Genetics and Molecular Biology, University of North Carolina, Chapel Hill, North Carolina 27599, USA \\ ${ }^{4}$ Bioinformatics and Computational Biology Program, University of North Carolina, Chapel Hill, North Carolina 27599, USA
}

\begin{abstract}
ZFP36L2 (L2) destabilizes AU-rich element (ARE)-containing transcripts and has been implicated in female fertility. We have shown that only one of three putative AREs within the $3^{\prime}$ UTR of murine luteinizing hormone receptor mRNA, ARE2197 (UAUUUAU), is capable of interacting with L2. To assess whether structural elements of ARE2197 could explain this unique binding ability, we performed whole-transcript SHAPE-MaP (selective $2^{\prime}$ hydroxyl acylation by primer extension-mutational profiling) of the full-length mLHR mRNA. The data revealed that the functional ARE2197 is located in a hairpin loop structure and most nucleotides are highly reactive. In contrast, each of the nonbinding AREs, 2301 and 2444, contains only a pentamer AUUUA; and in ARE2301 much of the ARE sequence is poorly accessible. Because the functional mARE was also found to be conserved in humans at the sequence level (ARE 2223), we decided to investigate whether binding and structure are also preserved. Similar to mouse, only one ARE in hLHR mRNA is capable of binding to L2; and it is also located in a hairpin structure, based on our SHAPE-MaP data. To investigate the role of secondary structure in the binding, we mutated specific nucleotides in both functional AREs. Mutations in the flexible stem region proximal to the loop that enforce strong basepairing, drastically reduced L2 binding affinity; this confirms that the structural context is critical for L2 recognition of hARE2223. Collectively, our results suggest that a combination of minimal ARE sequence, placement of the ARE in a hairpin loop, and stem flexibility mediate high-affinity L2 binding to hLHR mRNA.
\end{abstract}

Keywords: RNA-binding protein; ZFP36L2; infertility; post-transcriptional modulation; LHR mRNA

\section{INTRODUCTION}

Luteinizing hormone receptor (LHR) is critical for signaling downstream events that ultimately lead to ovulation and oocyte maturation in mammals. Expression of LHR is restricted to a few reproductive organs (Zhang et al. 2001; Ascoli et al. 2002) and specific neuronal cells (Lei et al. 1993). In the ovary, LHR mRNA expression is tightly controlled and its level fluctuates tremendously during the ovarian cycle; it is maximally expressed close to ovulation and drastically reduced (10-fold) immediately after ovulation (LaPolt et al. 1990). Its ligand, the luteinizing hormone (LH), is a major player in the regulation of receptor expression. In the ovary, LHR is detected in the follicles, theca cells, and corpus luteum (Bukovský et al. 1993). Ovarian LHR expression increases

\footnotetext{
${ }^{5}$ Present address: Biochemistry Department, University of Iowa, Iowa City, IA 52242, USA

${ }^{6}$ Present address: Biology Department, Hastings College, Hastings, NE, 68901, USA

Corresponding author: sramos@med.unc.edu

Article is online at http://www.rnajournal.org/cgi/doi/10.1261/rna.060467. 116.
}

gradually in the growing follicles by the combined actions of FSH and estradiol (Zeleznik 2004), whereas a drastic decrease in LHR mRNA abundance occurs after the LH surge (LaPolt et al. 1990). Degradation of the LHR mRNA is the main process responsible for this rapid decrease in expression (Lu et al. 1993). The mechanism of LHR transcript decay is not fully understood, but at least one protein, LHR mRNA binding protein (LRBP), binds to this transcript and accelerates its degradation (Hoffman et al. 1991; Menon et al. 2013).

We have previously shown that ZFP36L2, a protein that interacts with adenine-uridine-rich elements (ARE) in $3^{\prime}$ UTR of mRNAs, is also involved in modulating LHR mRNA levels (Ball et al. 2014). Two different strains of female mice expressing low levels of ZFP36L2 lacking $29 \mathrm{~N}$-terminal amino acids ( $\triangle \mathrm{N}$-ZFP36L2) exhibited complete infertility (Ramos

\footnotetext{
(c) 2017 Ball et al. This article is distributed exclusively by the RNA Society for the first 12 months after the full-issue publication date (see http:// rnajournal.cshlp.org/site/misc/terms.xhtml). After 12 months, it is available under a Creative Commons License (Attribution-NonCommercial 4.0 International), as described at http://creativecommons.org/licenses/by-nc/ $4.0 \%$.
} 
et al. 2004; Ball et al. 2014). The $\Delta \mathrm{N}-\mathrm{ZFP36L2}$ protein retained all biochemical properties of the wild-type ZFP36L2; it shuttles between the cytoplasm and the nucleus, binds to RNAs containing AREs, and it promotes deadenylation of a model ARE transcript (Ramos 2012). $\Delta N-Z f p 36 l 2$ homozygous females expressing low levels of $\Delta \mathrm{N}-\mathrm{ZFP} 36 \mathrm{~L} 2$ do not ovulate under superovulation protocols, and their oocytes collected directly from the ovaries and subjected to in vitro maturation remain arrested at the germinal vesicle $(\mathrm{GV})$ stage (Ball et al. 2014). This female infertility phenotype supports a role of ZFP36L2 in modulating ovulation and oocyte maturation. While investigating the mechanism underlying this phenotype, we found that ZFP36L2 binds the LHR mRNA and controls its expression levels in the ovary (Ball et al. 2014).

ZFP36L2 (ZFP36 zinc finger protein-like 2, also known as TIS11D [Varnum et al. 1991], BRF-2 [Maclean et al. 1998], and ERF-2 [Nie et al. 1995]) belongs to a small family of RNA-binding proteins, the Tristetraprolin (TTP) or TIS11 family (Varnum et al. 1991; Blackshear 2002). The tandem zinc finger domain of these proteins mediates binding to mRNAs containing ARE elements (Lai et al. 2000). In general, multiple ARE sequences in $3^{\prime}$ UTRs are thought to act in concert with RNA-binding proteins to increase sensitivity and specificity of regulatory interactions. Thus, mRNAs containing AREs were originally subdivided into three classes depending on the motifs they possess. Class I AREs contain an AUUUA motif and a U-rich region, whereas Class II and III contain only AUUUA motifs or a U-rich region, respectively (Xu et al. 1997). Class II has been subdivided depending on the number of AUUUA repeats (Bakheet et al. 2001). Class IIA contains five consecutive AUUUA elements, Class IIB four, Class IIC three, Class IID two, and Class IIE contains only one AUUUA motif (Bakheet et al. 2001). One accepted property of the TTP family of RNA-binding proteins is that they bind to mRNA targets containing clusters of consecutive AUUUA of the Class IIA type (Lai et al. 2000), such as are present in tumor necrosis factor $\alpha(\mathrm{TNF}-\alpha)$ and granulocyte macrophage-colony stimulation factor (GM-CSF). Also, in gel shift assays, all three human family members, TTP, ZFP36L1, and ZFP36L2, bind comparably to probes containing clusters of AREs (Lai et al. 2000; Ball et al. 2014), suggesting lack of binding specificity among these proteins when the mRNA targets contain class IIA AREs. The optimum RNA-binding sequence for this family of proteins is believed to be a nonamer UUAUUUAUU nucleotide sequence (Worthington et al. 2002; Blackshear et al. 2003; Brewer et al. 2004; Lai et al. 2005).

Strikingly, our previous results of the interaction between ZFP36L2 and murine LHR mRNA demonstrate that a single ARE (Class IIE) functions in regulating LHR mRNA levels, because only one ARE (ARE 2197) is necessary and sufficient to mediate binding of ZFP36L2. Also, the other TTP family members (TTP and ZFP36L1) did not bind to ARE2197 (Ball et al. 2014), suggesting that the ZFP36L2/LHR mRNA recognition is highly specific. Curiously, ARE2197 is a hep- tamer (UAUUUAU), which is smaller than the expected optimum RNA-binding sequence. Given these characteristics, we sought to determine whether this particular ARE has any potential structural conformation beyond its linear sequence that might contribute to protein recognition. To obtain the structure of mLHR mRNA, we used selective $2^{\prime}$ hydroxyl acylation by primer extension and mutational profiling (SHAPE-MaP) using next-generation sequencing (Siegfried et al. 2014). Our detailed RNA structural analysis combined with quantitative binding experiments revealed an intricate interplay of sequence and structure driving the function of a single ARE in the LHR mRNA.

\section{RESULTS}

\section{Knockdown of ZFP36L2 abolishes decay of LHR mRNA}

Previously, using our $\Delta N-Z f p 36 l 2$ homozygous hypomorphic females, we observed a twofold increase in LHR mRNA abundance in synchronized ovaries (immediately post-estrous) from animals expressing low levels of ZFP36L2 compared with wild-type littermates (Ball et al. 2014). Conversely, using a cell line, we observed that overexpression of ZFP36L2 decreases endogenously expressed LHR mRNA (Ball et al. 2014). Collectively, these support our hypothesis that ZFP36L2 binds and destabilizes LHR mRNA under physiological conditions. Now, to directly investigate the effect of ZFP36L2 on LHR mRNA decay, we used a short-hairpin RNA (shRNA) to specifically knock down ZFP36L2 in the cell line MLTC-1, which is derived from an LHR-expressing tissue and also maintains LHR expression in culture. Following treatment with the global transcription inhibitor, actinomycin D, we measured endogenous LHR mRNA levels by qRT-PCR at various time points. Upon ZFP36L2 knockdown, LHR mRNA remained relatively stable after inhibiting transcription (Fig. 1A, red squares), whereas it was degraded (Fig. 1A, blue circles) in control cells infected with the empty shRNA vector. Figure 1B shows knockdown efficiency. The results of this cell-based assay clearly support a role for ZFP36L2 in the control of LHR mRNA degradation and reinforce our initial in vivo observation of higher levels of LHR mRNA in $\Delta N-Z f p 36 l 2$ homozygous females expressing lower levels of ZFP36L2. We next aimed to further dissect the molecular basis of this regulation.

\section{mZFP36L2-HA binds to only ARE2197 in mouse LHR MRNA}

A bioinformatic analysis identified three putative AREs in the 3' UTR of the mouse LHR transcript. The location of these AREs is schematically shown in Figure 1C. Previously, by gel shift assays, we found that mZFP36L2-GFP, but not the other family members, binds to only one of these three AREs (Ball et al. 2014). We used RNAfold (Hofacker and Stadler 2006) to design probes containing each ARE in its 


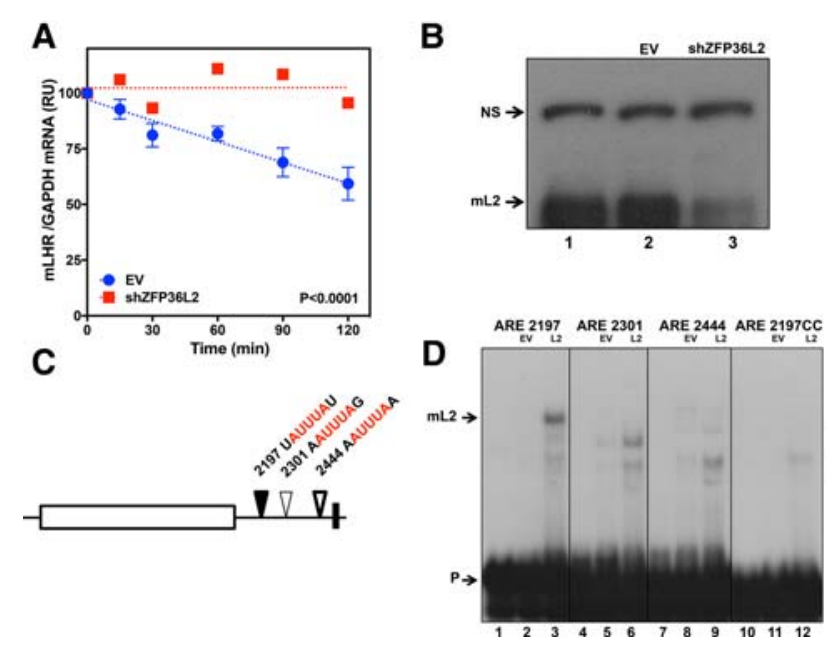

FIGURE 1. mLHR mRNA decay is dependent on ZFP36L2. (A) MLTC1 cells infected with lentivirus without (EV) or with an shRNA targeting ZFP36L2 (LV9) were treated with actinomycin D $(4 \mu \mathrm{g} / \mathrm{mL})$ for $30 \mathrm{~min}$ before the time course initiation. Total RNA was harvested from cells at six different time points. LHR and GAPDH mRNAs were quantitated in triplicate by qRT-PCR. The graphic was built from results of two biological replicates. The slopes are different $(P<$ 0.0001). (B) Immunoblot using protein extracts confirmed knockdown of ZFP36L2 (lane 3) in comparison to WT MLTC-1 cells (lane 1) or cells treated with the empty vector (lane 2). (NS) Nonspecific, cross-reacting protein serving as loading control. $(C)$ Schematic location of AREs present in the mouse LHR transcript. AREs located at the $3^{\prime}$ UTR are represented by triangles followed by its respective number, each pentamer sequence composing the ARE (red) is flanked by one nucleotide. (D) RNA electrophoretic mobility shift assays were performed by incubating protein extracts from HEK 293 cells transfected with either the empty vector $(\mathrm{EV}, 5 \mu \mathrm{g}$, lanes $2,5,8,11)$ or with a vector expressing mZFP36L2-HA (L2, $10 \mu \mathrm{g}$, lanes $3,6,9,12$ ) with $0.2 \times 10^{5} \mathrm{cpm}$ of mLHR ARE probes. In probe 2197CC, both "As" of ARE2197 were mutated to "Cs." Lanes 1,4,7,10 contain each probe without any protein extracts, but only buffer. When $5 \mu \mathrm{g}$ of protein extracts lacking ZFP36L2 protein (lanes 2,5,8,11) were incubated with each probe, faint bands appeared (indicated by asterisks). They correspond to complexes of endogenous proteins present in HEK 293 cells that interact with the probes. These bands are more evident in lanes 3,6,9,12, because more total protein extracts $(10 \mu \mathrm{g})$ containing overexpressed ZFP36L2 were used.

native predicted structure (for probe sequence see Materials and Methods). RNA gel shift assays using these new probes and protein extracts from HEK cells transfected with a mZFP36L2-HA construct instead of mZFP36L2-GFP construct as in Ball et al. 2014. mZFP36L2-HA bound the LHR mRNA probe containing the ARE located at nucleotide 2197 (Fig. 1D, lane 3), consistent with our previous results. When we changed both " $\mathrm{A}$ " nucleotides in the heptamer UAUUUAU to "C" (ARE 2197CC probe), binding to ZFP36L2 was abolished (Fig. 1D, cf. lane 12 and lane 3), suggesting that the interaction is indeed mediated by this specific AUUUA sequence in the $3^{\prime}$ UTR. Interestingly, no specific ZFP36L2 binding was observed when we used probes containing ARE sequences located at 2301 or 2444 (Fig. 1D, lanes 6 and 9, respectively), consistent with our previous findings (Ball et al. 2014). Of note, HEK cells do not express ZFP36L2, but as seen in the control condition when an empty vector was transfected, other proteins endogenously expressed by these cells can interact with the probes. Asterisks $\left({ }^{*}\right)$ indicate these protein complexes that can form in the absence of ZFP36L2.

\section{Mutation in the tandem zinc finger domain of mZFP36L2 disrupts RNA binding}

We next changed the third cysteine to a serine in the first zinc finger from the tandem zinc finger domain (TZF) of mZFP36L2; this mutant protein is unable to bind mLHR ARE 2197 probe (Fig. 2A, lane 4). Wild-type and TZF mutant proteins were present at similar levels in extracts from HEK 293 cells transfected with their respective plasmids (Fig. 2B). Previously, we observed that despite sharing extensive homology in their zinc finger domains, the other TTP family members did not bind to ARE 2197 (Ball et al. 2014).

\section{SHAPE-MaP reveals structural features of mouse LHR mRNA}

The AUUUA motif is a hallmark of short-lived mRNAs, but the exact recognition sequence varies for different RNA-binding proteins. In addition, the role of sequence and structural context in the recognition process are poorly understood. To assess the potential influence of RNA structure on protein recognition, we used SHAPE-MaP (Siegfried et al. 2014) to determine the secondary structure of full-length mouse LHR mRNA (2531 bp). SHAPE-MaP provides a biophysically rigorous measurement of local nucleotide flexibility that is independent of base identity, in contrast to other structureprobing techniques, such as enzymatic cleavage or modification by dimethyl sulfate (DMS) and $N$-cyclohexyl- $N^{\prime}-$ (2-morpholinoethyl) carbodiimide (CMCT) (Kertesz et al. 2010; Ding et al. 2014; Incarnato et al. 2014; Rouskin et al. 2014; Wan et al. 2014). SHAPE-MaP uses the selective reactivity of 1-methyl-7-nitroisatoic anhydride (1M7) to probe unpaired or flexible nucleotides, thus providing a structural profile of an entire transcript with single-nucleotide resolution. The SHAPE-MaP data for the full-length mouse LHR transcript are illustrated using a median window average in Figure 3A. Contiguous regions with SHAPE-MaP values below the median are considered structured. Conversely, above zero are regions predicted to have low probability of being structured based on a $z$-score analysis on a windowed free energy of folding (Soldatov et al. 2014). As described for other mRNAs, the $5^{\prime}$ end of the LHR message is highly structured. Interestingly, two other areas close to the $5^{\prime}$ end but within the coding sequence are highly structured (Supplemental Fig. 1) and correspond to the nucleotides wherein LHRBP binds to LHR mRNA (Kash and Menon 1999). Also, as observed in other transcripts, the area close to the stop codon is structured (low median SHAPE) (Del Campo et al. 2015). Conversely, positive SHAPE-MaP values indicate a lack of structural features within the $3^{\prime}$ UTR of the message (Fig. 

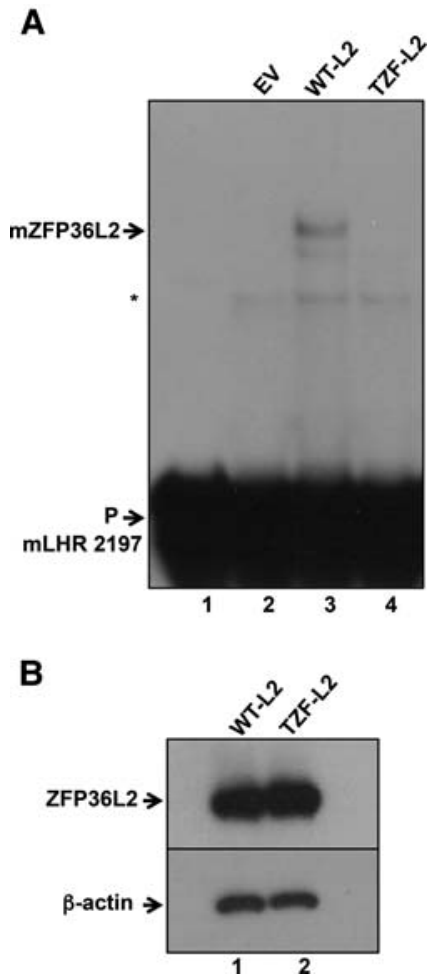

FIGURE 2. C176S mutation in mZFP36L2 abolishes binding to the mLHR ARE 2197 probe. (A) RNA electrophoretic mobility shift assays were performed by incubating protein extracts from HEK 293 cells transfected with the empty vector $(\mathrm{EV}, 5 \mu \mathrm{g}$, lane 2$)$, a vector expressing mZFP36L2-HA (WT-L2) or TZF-Mut-mZFP36L2(C176S)-HA (TZFL2) $\left(10 \mu \mathrm{g}\right.$ of each in lanes 3 and 4 , respectively), with $0.2 \times 10^{5} \mathrm{cpm}$ of the mLHR ARE 2197 probe. The input probe in buffer was analyzed in lane 1. (B) Immunoblotting of $10 \mu \mathrm{g}$ of protein extracts from HEK 293 cells transfected with mZFP36L2-HA (WT-L2, lane 1), or TZFMut-mZFP36L2-HA (TZF-L2, lane 2), were probed with an anti-HA antibody (upper panel). An anti- $\beta$ actin antibody was used as a loading control (lower panel). These protein extracts were aliquots of the same material used in lanes 3 and 4 of the gel shift assay shown in panel $A$, respectively.

$3 \mathrm{~A})$. In Figure $3 \mathrm{~B}$, the raw SHAPE-MaP data are shown specifically for the $5^{\prime}$ and $3^{\prime}$ UTRs of this transcript. Each bar represents the individual reactivity for each single nucleotide obtained from two distinct preparations of the transcript. The error bars illustrate the result of error propagation for the distinct replicates (Supplemental Table Data). Visualization of the raw SHAPE reactivity is enhanced using a color code; red corresponds to a nucleotide with high reactivity (flexible and therefore likely unpaired), and orange and black correspond to moderate and low nucleotide reactivity, respectively. We used this data to inform a SHAPE-directed RNA structural model (Deigan et al. 2009), which is illustrated in Figure 3C. The SHAPE data are incorporated in the structural model as an additional free energy term (Deigan et al. 2009). As a result, the structural model is consistent with the SHAPE data (Fig. 3A) and has greater structure at the $5^{\prime}$ end and CDS compared with the $3^{\prime}$ UTR in agreement with the low to high gradient of median SHAPE observed in the data. However, when we zoomed in the area surrounding the AREs, we noticed that the functional ARE2197 is located in a hairpin loop (Fig. 3C, inset I). ARE2301 is not within a hairpin loop (Fig. 3C, inset II), and ARE2444, despite being predicted to be in a hairpin loop (Fig. 3C, inset III), contains only a pentamer AUUUA sequence, suggesting that it lacks the minimal sequence able to support the RNA-protein interaction. Based on these results, we propose that a functional ZFP36L2-specific ARE is located in a hairpin loop and that this structure might influence or even favor the reactivity of the ARE. Thus, we sought next to determine whether this feature is evolutionarily conserved.

\section{Sequence comparison of mouse and human LHR transcripts}

To determine the level of sequence conservation in the mouse $3^{\prime}$ UTR, we performed sequence alignments of mammalian LHR 3' UTRs, and compared these alignments to the AREs present in mouse and human (Fig. 4A). Among the species analyzed, mouse ARE2197 is more conserved than the other two AREs, 2301 and 2444. The heptamer (UAUUUAU) in mouse ARE2197 is present in nine of the 10 species examined, including human (corresponding to ARE2223) (Fig. 4A). The mouse ARE2301 (pentamer AUUUA) is not conserved, being present in only mouse and rat. Interestingly, mouse ARE2444 (pentamer AUUUA) is found in seven of the 10 species analyzed, including human. In summary, as illustrated in Figure $4 \mathrm{~B}$ and $\mathrm{C}$, both mouse and human LHR transcripts contain three AREs upstream of the poly(A) signal. Two of these three AREs are found in both mouse and human (black and bold triangles in Fig. 4B,C), whereas ARE2301 is present only in mouse, and ARE2211 is present only in humans (plain triangles in Fig. 4B,C).

\section{mZFP36L2 and hZFP36L2 bind to a single ARE in the human LHR transcript}

To dissect the functional properties of the three ARE sequences in the human LHR mRNA, we performed RNA gel shift assays with mZFP36L2-HA, using the same probe design principles that we used for the mouse LHR mRNA probes. Based on the alignment, human ARE2223 corresponds to mouse ARE2197, and thus we would anticipate hARE2223 to exhibit binding to ZFP36L2. Indeed, mZFP36L2 did bind the human ARE2223 probe (Fig. 5A, lane 6, L2 arrow). When we changed both " $A$ " nucleotides in the nonamer UUAUUUAUU to "C," binding to mZFP36L2 was abolished (Fig. 5A, cf. lane 12 and lane 6). Based on the sequence alignment, mouse ARE2444 corresponds to human ARE2490, and, like mouse ARE2444, human ARE2490 did not bind mZFP36L2 (Fig. 5A, lane 9). Finally, a probe containing the ARE sequence located at 2211, which is unique to the human transcript, also did not bind to ZFP36L2 (Fig. 5A, lane 3). In summary, only mouse ARE2197 and human ARE2223 bind 

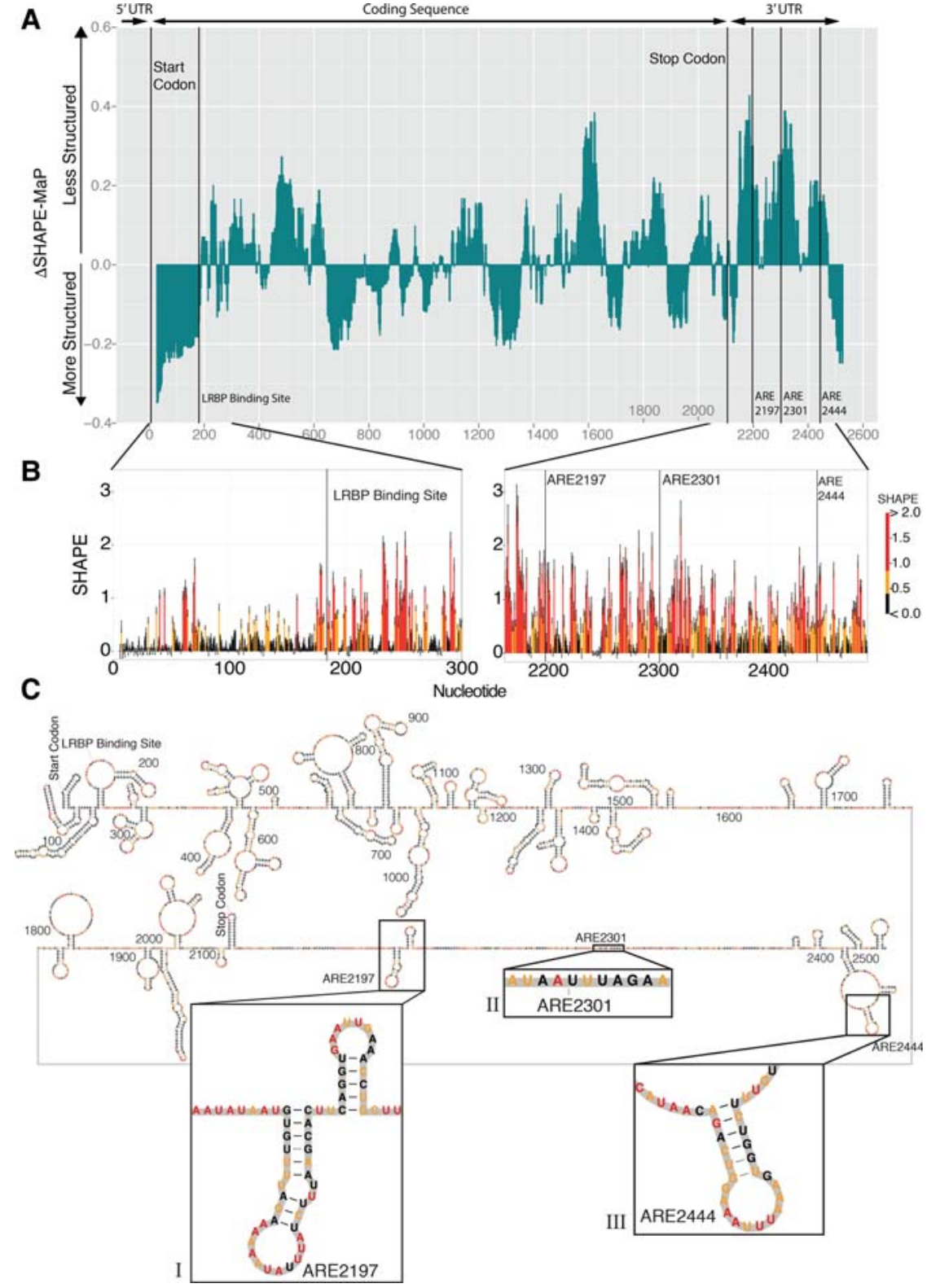

FIGURE 3. Structural architecture of mouse LHR mRNA. (A) In vitro $1 \mathrm{M} 7$ reactivity for the fulllength mouse LHR transcript was obtained and represented as median reactivity relative to the global median. The median-averaged signal was used to identify regions of high-median SHAPE reactivity (above zero), which correspond to less structured areas. Similarly, SHAPE nucleotides with a low median reactivity (below zero) correspond to more structured areas in the transcript. (B) SHAPE data for each individual nucleotide composing the $5^{\prime}$ end of LHR transcript (left) and $3^{\prime}$ UTR illustrate a difference between high structure (low SHAPE) and low structure (high SHAPE). In general, the median SHAPE reactivity increases from $5^{\prime}$ to $3^{\prime}$, indicating less base-pairing in the $3^{\prime}$ UTR. (C) SHAPE-informed secondary structure model of mouse LHR transcript. Zooming in the functional ARE 2197 reveals a typical hairpin (inset I). AREs 2301 and 2444 are shown in insets II and III, respectively.

to ZFP36L2 (black triangles in Fig. 4B,C), whereas hARE2490, despite being conserved, did not exhibit binding similar to mouse ARE2444 (bold triangle in Fig. 4B,C).

Mouse and human ZFP36L2 proteins have barely diverged. They are $83 \%$ identical in overall amino acid sequence, and they share $100 \%$ sequence identity in their tandem zinc finger domain. Given that binding relies on the TZF domain, we tested whether mouse and human proteins binding to hLHR ARE2223 are comparable. To test that we did a dose response of mouse and human proteins in gel shift assays using the hLHR ARE2223 probe, as shown in Figure 5B. Quantification of these dose responses (Fig. 5C) suggested that both proteins bind to this ARE with comparable affinity. Note that the mZFP36L2-HA construct resulted in slightly higher protein expression (Fig. 5D, left panel) when compared with hZFP36L2-DDK (Fig. 5D, right panel). Accordingly, this explained the slightly higher affinity of mL2-HA seen in Figure 5C. Given that both proteins had comparable affinities, we decided to use only $\mathrm{mL} 2$ for the next experiments as it expresses slightly better than hL2.

\section{SHAPE-MaP reactivity revealed structural features shared between human and mouse LHR mRNA AREs}

The observation that ZFP36L2 bound to only a single ARE in both mouse and human LHR mRNAs prompted us to collect SHAPE-MaP data for the full-length human transcript (2534 bp). The data are shown in Figure 6. Not surprisingly, a similar general pattern of RNA structure was observed for the human LHR transcript, wherein the $5^{\prime}$ end, CDS, and the vicinity of the stop codon showed defined structured regions (Fig. 6A). Analogous to the mouse LHR SHAPE-directed structure, our human structural model (Fig. 6C) also includes a higher density of hairpins and stem-loops in areas expected to be more structured, in agreement with the median SHAPE data (Fig. $6 \mathrm{~A})$. Intriguingly, the functional human ARE2223 is also located in a hairpin loop (Fig. 6C, inset I) similar to the functional mouse ARE2197 (Fig. 3C, inset I). The nucleotides of human ARE2211 displayed very low SHAPE reactivity and are likely paired (Fig. 6C, inset I), and thus they are not prone to interaction. Finally, human ARE2490 displayed high SHAPE reactivity and is located in a hairpin loop (Fig. 6C, inset II) similar to mouse ARE 2444. Human ARE2490 had no binding activity in gel shift assays, and it contains only a pentamer AUUUA sequence. Thus, human ARE2490, analogous to 
A

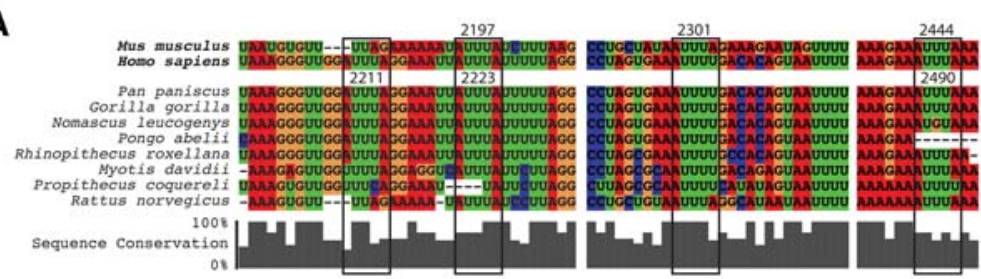

B
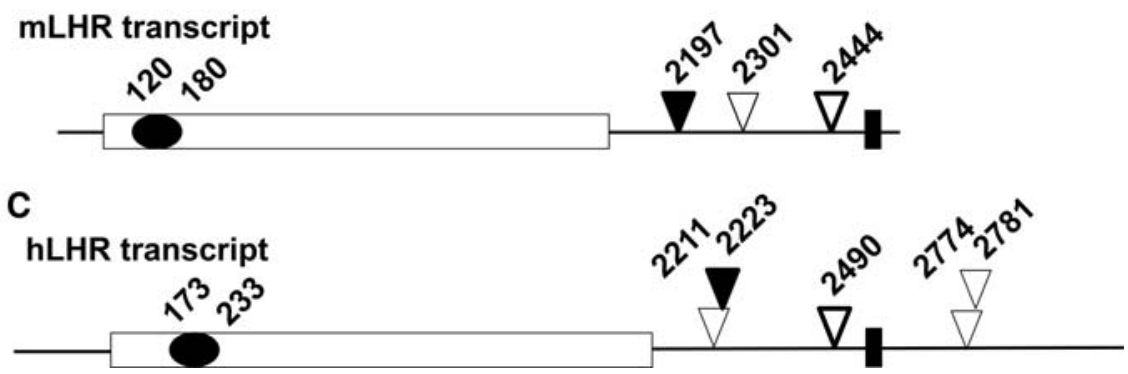

FIGURE 4. Multispecies alignment of Adenine-Uridine-rich elements (AREs) within the $3^{\prime}$ untranslated region of luteinizing hormone receptor transcript. (A) Conserved AREs are outlined by black boxes. Mouse (Mus musculus) and Human (Homo sapiens) AREs are numbered according to the position of the first $5^{\prime}$ adenosine of the ARE. Conservation was computed for each position in the alignment and reported as gray vertical bars below each column. Mouse ARE 2197 and 2444 are highly conserved, while human ARE 2211 is present only in some primate species. Schematic drawing of mouse $(B)$ and human $(C)$ LHR transcripts. The lines represent untranslated regions, and the open rectangles correspond to coding sequence. The relative location of each ARE is represented by a triangle. The black rectangle at the $3^{\prime}$ UTR illustrates the location of the poly (A) signal. Two of these three AREs are present in mouse and human (bold and black triangles). However, only ARE 2197 binds ZFP36L2 (black triangles), whereas the conserved ARE 2444 did not show binding (bold triangles). mARE 2301 and hARE 2211 are not conserved (plain triangles). Downstream from the poly(A) signal, the human LHR transcript has two other AREs (2774 and 2781) that are not present in the mouse mRNA, and they were not investigated here. Within the coding region of the mouse and human transcripts, a polypyrimidine rich track corresponds to the LRBP binding site (dark ellipse).

mouse ARE2444, lacks the minimal nucleotide sequence able to elicit an RNA-L2 protein interaction.

\section{mZFP36L2 binds human ARE2223 more strongly than mouse ARE2197}

Because mouse ARE2197 and human ARE2223 both bound to mZFP36L2, and both AREs exhibited high sequence identity and similar surrounding structures, we sought to further explore their interaction with L2. Interestingly, when we incubated equivalent amounts of the ARE probes with the same amount of protein extracts overexpressing mZFP36L2-HA, and subjected the mixes to a side-by-side gel shift assay, we observed that the interaction of mZFP36L2 with the mouse ARE2197 probe was dramatically weaker (Fig. 7A,D) compared with that observed with the human ARE2223 probe (Fig. 7C,D). Both AREs are located in a hairpin loop (Fig. 7A,C, structural insets), but the human ARE2223 has a nonamer UUAUUUAUU, whereas the mouse ARE has a heptamer UAUUUAU sequence. To determine whether the nonamer was the main determinant of the higher affinity of mZFP36L2-HA for the human ARE, we mutated the two flanking nucleotides of the mouse ARE to uridines and assessed the affinity in a dose-dependent manner. The ideal nonamer increased the binding affinity in regard to the WT mARE (Fig. 7B,D), but it was still threefold lower than affinity for the human ARE2223, suggesting that other aspects of local RNA secondary structure may influence the affinity for mZFP36L2.

Because hARE 2211 is only 7 nt apart from hARE 2223 and is in the same RNA structural domain (Fig. 6C, inset I), we questioned whether nonbinding ARE2211 could exhibit binding if present in the same probe as the functional hARE2223. Therefore, we designed a probe containing both AREs, as shown in Figure $8 \mathrm{~A}$, and added increasing amounts of mZFP36L2 (Fig. 8B). The hARE2211_2223 probe binds similarly to the one containing only hARE2223, but it appears to have a slightly weaker interaction (Fig. 8C); however, both probes resulted in similar maximum binding (Fig. 8C). These data demonstrate that ZFP36L2 does not bind to the hARE2211, whether it is isolated as in the hARE2211 probe (Fig. 5A) or together with another functional ARE as in probe hARE2211_2223. In this particular case, these two AREs do not seem to work synergistically, likely because the 5 nt of AUUUA composing ARE2211 are insufficient to bind to the $\mathrm{ZFD}$, and this region is also base-paired in the structure of the probe.

\section{The structural flexibility of the hairpin stem in the ARE is a key component of protein interaction}

To test whether RNA secondary structure might influence the interaction with ZFP36L2, we mutated nucleotides outside of the human ARE2223 nonamer (UUAUUUAUU) sequence, aiming to stabilize the hairpin stem-loop. For that we replaced two uridines downstream from the ARE with cytosines (Fig. 9C, in green), resulting in a stem structure more rigid than the wild-type stem. The affinity of this mutant, hARE2223 C3C4, for mZFP36L2 was dramatically weaker (Fig. 9B,D). To better understand this result, we used the SHAPE reactivity of each nucleotide in the vicinity of the ARE to estimate the ensemble base-pairing probability (Bellaousov et al. 2013). When we performed this calculation for the vicinity of mARE2197 and hARE2223, we found lower base-pairing probability around the hARE2223 (Fig. 9E, lower panel) in comparison to mARE 2197 (Fig. 9E, upper 
A

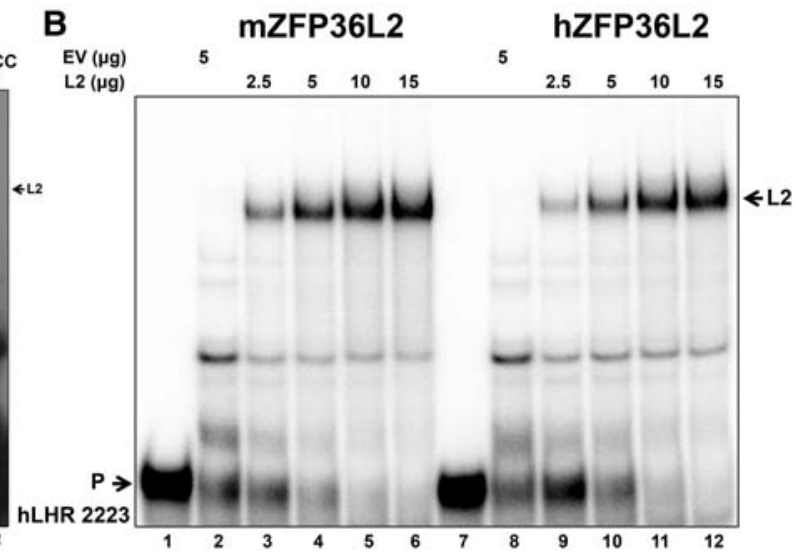

C
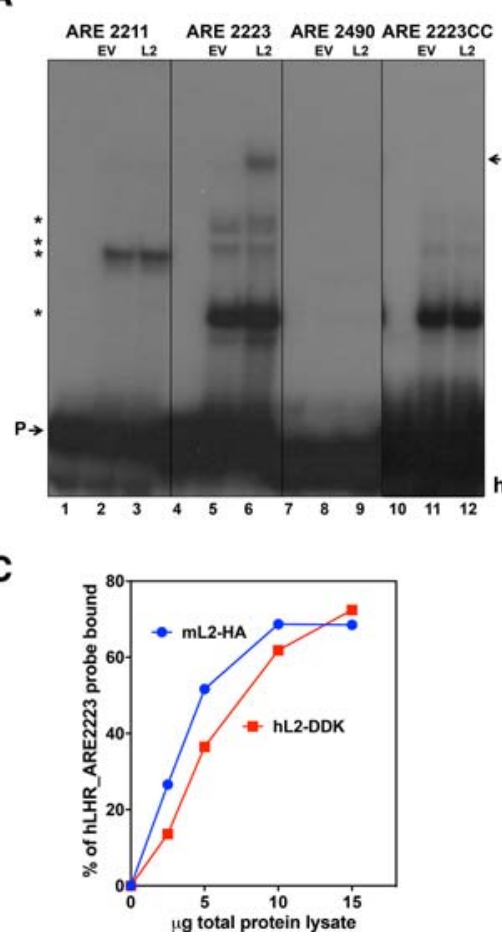

D

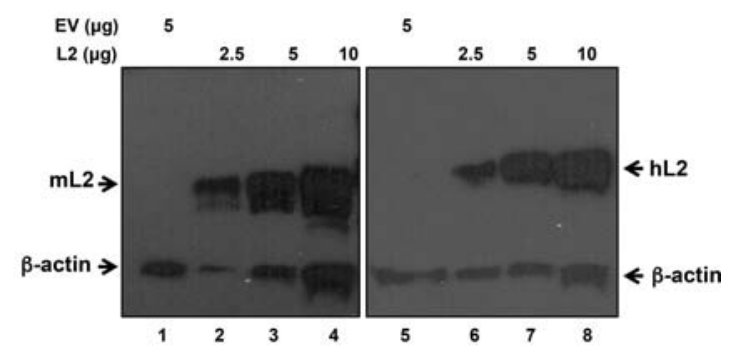

FIGURE 5. mZFP36L2 and hZFP36L2 bind to ARE2223 from the human LHR transcript. (A) RNA electrophoretic mobility shift assays were performed by incubating protein extracts from HEK 293 cells transfected with empty vector (EV, $10 \mu \mathrm{g}$, lanes $2,5,8,11$ ) or with a vector expressing mZFP36L2-HA (L2, $10 \mu \mathrm{g}$, lanes 3,6,9,12), with $0.2 \times 10^{5} \mathrm{cpm}$ of each hLHR ARE probe, as indicated on top of the lanes. In probe $2223 \mathrm{CC}$, both "As" of ARE were mutated to "Cs." Lanes 1,4,7,10 contain each input probe in the presence of buffer only. Note that when equivalent amounts of protein extract lacking ZFP36L2 (lanes 2,5,8,11) or containing overexpressed mZFP36L2 were incubated with probes, unspecific bands (indicated by asterisks) of comparable intensity are observed. They correspond to complexes of endogenous proteins present in HEK 293 cells that interact with the probes. $(B)$ Increasing amounts of overexpressed mZFP36L2-HA or hZFP36L2-DDK were tested for the ability to shift the electrophoretic mobility of the hARE2223 probe. Protein extracts were used in the following sequence: lanes 1 and 7 , input probe incubated with buffer; lanes 2 and 8 contained $5 \mu \mathrm{g}$ of protein extract from HEK cells transfected with an empty vector; lanes 3-6 correspond to mZFP36L2-HA; and lanes 9-12 to hZFP36L2-DDK of incremental amounts of protein, as shown in the top. $(C)$ Dose-response curves of mZFP36L2-HA (blue circles) and hZFP36L2-DDK (red squares) to the hARE2223 probe were constructed based on quantifications of the bound and unbound probes. $(D)$ Immunoblotting of protein extracts from HEK 293 cells transfected with EV (lanes 1 and 5), mZFP36L2-HA (lanes 2-4), or hZFP36L2-DDK (lanes 6-8) constructs were probed with an anti-HA antibody (left) or anti-DDK antibody (right). An anti- $\beta$ actin antibody was used as a loading control (lower arrow). These protein extracts were aliquots of the same material used in lanes 3-5 or 9-11 of the gel shift assay shown in panel $B$, respectively.

panel). Thus, nucleotides close to hARE2223 are more prone to interact than the ones close to mARE2197, explaining the higher binding affinity of mZFP36L2 to the hARE2223 compared to mARE2197.

Alternatively, one could argue that a decrease in binding with the mutant hARE2223 C3C4 was not due to stabilization of the stem, but rather due to the loss of a string of $U$ residues that could interact specifically with the protein. To test this we first designed a mutation that would affect the stability of the stem but conserve the string of "Us," as shown in Figure 10A. The binding to the hARE2223 CC disrupted the interaction in a similar way as seen with hARE2223 C3C4 (Fig. 10D), suggesting that this string of $U$ residues are not responsible for the high affinity interaction as much as the flexibility of the stem. Thus, we designed a second mutation preserving the $U$ string, but now mutating the opposing "Gs" to "As," preserving the stem structure, as illustrated in Figure 10B. The binding affinity to hARE2223 AA was comparable to the WT structure (Fig. 10D), supporting our hypothesis that the stem structure is responsible for the high affinity. Lastly, we recreate the same base-pairing as in hARE 2223 C3C4, but now inverting the location of the "Cs" and "Gs" (Fig. 10C), based on the knowledge that the string of "Us" is not as relevant. This mutant recapitulates what we observed with hARE2223 C3C4, confirming that a rigid stem decreases the binding affinity.

Our findings are summarized in Figure 11. The highest binding affinity to mZFP36L2 was observed using the hARE2223 probe, containing the nonamer sequence (large font) located in the loop of a flexible stem. The second highest affinity was seen in hARE2223AA, followed by the mARE2197UU probe, which has a nonameric sequence similar to the one present in hARE2223. On the low affinity group we included mARE2197 containing a heptameter sequence (large font) and hARE mutants $2223 \mathrm{C} 3 \mathrm{C} 4$ and 2223 CCG3G4 containing nucleotides that stabilized the 


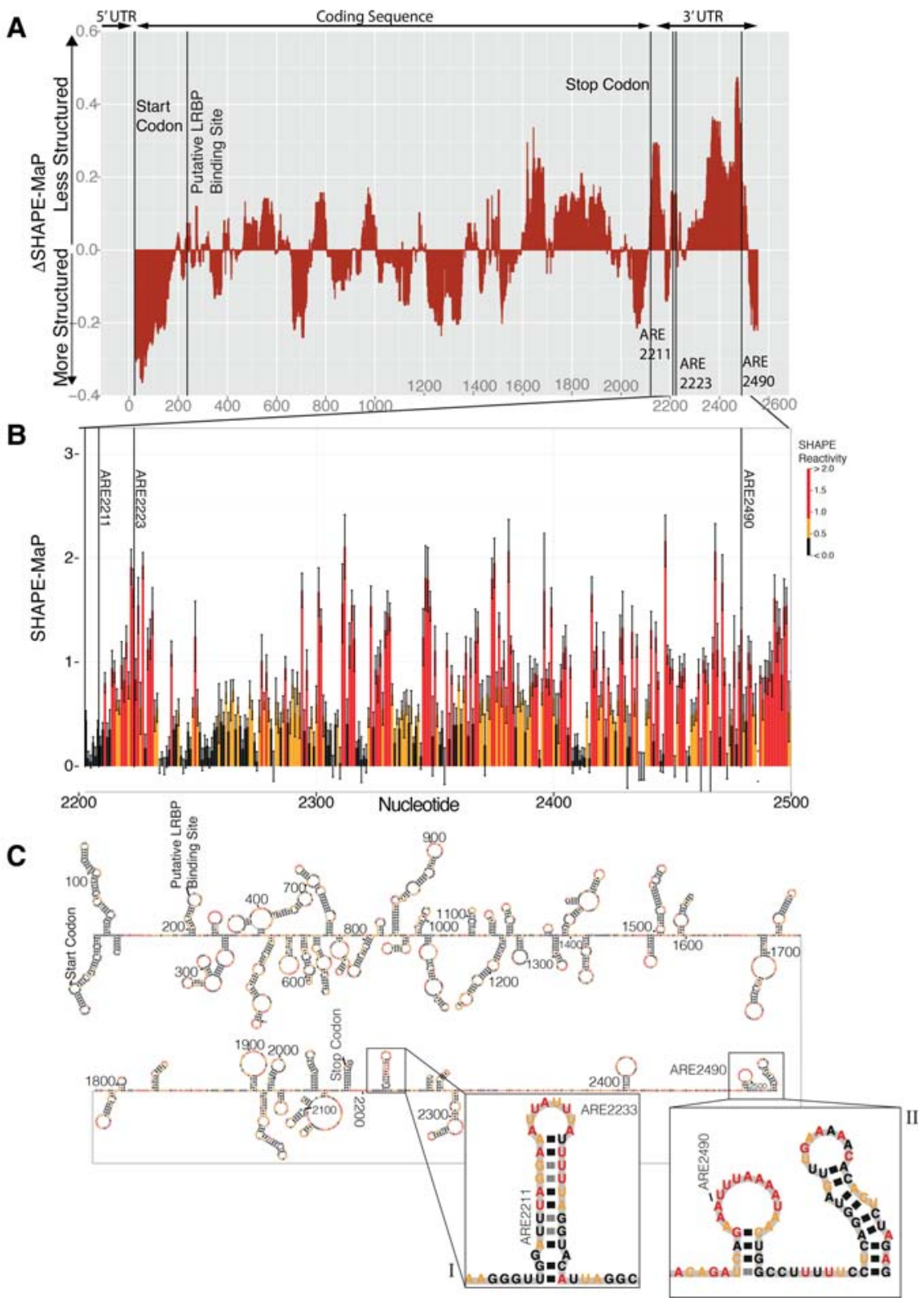

FIGURE 6. SHAPE-MaP structural analysis of the human LHR transcript. (A) Windowed SHAPE-MaP median difference identifies regions that are likely structured. Contiguous regions of below median average SHAPE reactivity are more likely to adopt a single, well-defined structure (Siegfried et al. 2014; Lavender et al. 2015). Structured areas generally overlap with experimentally identified windows of low SHAPE reactivity. The $3^{\prime}$ UTR of this transcript shows above-median reactivity, indicating that this region is less structured than the coding sequence. $(B)$ Raw SHAPEMaP signal covering the three ARE elements in the human LHR 3' UTR, averaged over two biological replicates; error bars indicate propagation of estimated error analysis. The low average error indicates high-reproducibility in the data. $(C)$ SHAPE-informed secondary structure model of human LHR transcript. Zooming in on the functional ARE2223 reveals a hairpin (inset I) similar to mARE2197. AREs 2211 and 2490 are shown in insets I and II, respectively.

\section{DISCUSSION}

A connection between the RNA-binding protein ZFP36L2 and the luteinizing hormone receptor (LHR) mRNA emerged from our previous biological investigation of the function of ZFP36L2 (Ball et al. 2014). Here we tested for the first time a role of ZFP36L2 in the decay of LHR mRNA, when transcription was inhibited. To do so, we used MLTC-1 cells, which express endogenous LHR and ZFP36L2. When MLTC-1 cells were transduced with an empty shRNA vector, the LHR mRNA was degraded with a half-life of $\sim 120 \mathrm{~min}$ (Fig. 1A). In contrast, when ZFP36L2 was knocked down with an shRNA-containing construct, the level of LHR mRNA did not change significantly. These results show that LHR mRNA is post-transcriptionally controlled by ZFP36L2. Interestingly, the LHR mRNA half-life we obtained using MLTC- 1 cells is comparable to the previously observed half-life for this transcript in granulosa cells (Kash and Menon 1998; Menon and Menon 2014), suggesting that our assay conditions in MLTC-1 cells recaptured this particular physiological process described in granulosa cells. Therefore, the results of our cell-based assay support the conclusion that LHR mRNA expression is controlled posttranscriptionally by ZFP36L2.

ZFP36L2 interacts with a specific sequence, ARE2197, located within the mouse LHR mRNA 3' UTR. This interaction requires both the adenine nucleotides in the heptamer sequence UAUUUAU and the tandem zinc finger domain of ZFP36L2. We draw these conclusions because both the adenine-tocytosine mutations in the UAUUUAU sequence (Fig. 1D) or the C176S ZFP36L2 mutant (Fig. 2A) completely abolished the protein-RNA interaction. Analogously, mutation of a single cysteine in either zinc finger to an arginine completely abrogated TTP interaction with a TNF- $\alpha$ probe (Lai et al. 2000).

stem and greatly reduced the interaction to ZFP36L2 (90\% decrease). The four other AREs tested, mARE2301, mARE2444, hARE2211, and hARE2490, contain only a pentamer sequence (large font) and did not interact with ZFP36L2.
However, in contrast to the dogma that TTP proteins interact only with transcripts containing clusters of ARE (class IIA), a single ARE, mARE2197 (Fig. 1), or hARE2223 (Fig. 5) seems to be sufficient for ZFP36L2 to interact with this target mRNA. 


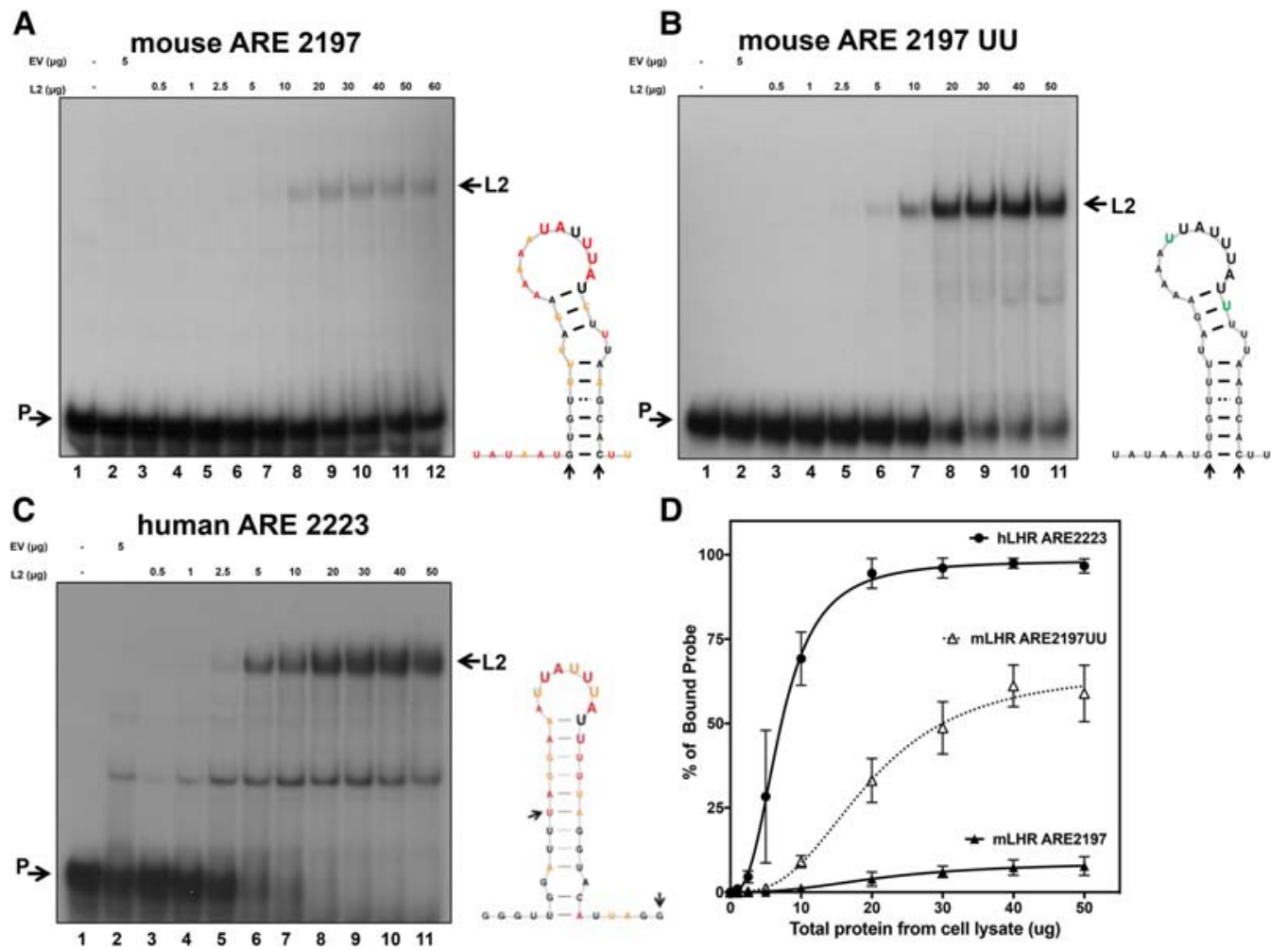

FIGURE 7. Binding and structural comparison of functional mouse and human AREs. Increasing amounts of overexpressed mZFP36L2-HA were tested in a dose-dependent manner for the ability to shift the electrophoretic mobility of the mouse ARE2197 (A), mouse mutant ARE2197UU $(B)$, and the human ARE2223 $(C)$ probes. In all three gels, protein extracts were used in the following sequence: lane 1 , input probe incubated with buffer, in the absence of protein extracts; lane 2 contained $5 \mu \mathrm{g}$ of protein extract from HEK cells transfected with an empty vector; lanes 3-11 contained protein extract from HEK cells transfected with a vector directing expression of mZFP36L2-HA; with incremental amounts of protein: 0.5, 1, 2.5, $5,10,20,30,40$, and $50 \mu \mathrm{g}$, respectively. Panel $A$ has one extra lane (lane 12) corresponding to $60 \mu \mathrm{g}$ of protein extract. In panel $D$, we noticed that binding was saturated at 30-50 $\mu \mathrm{g}$ of protein; thus, we removed this experimental point from the next experiments, corresponding to panels $B$ and C. (D) Curves of dose-response to mZFP36L2-HA for the mouse ARE2197, mouse mutant ARE2197UU, and human ARE2223 probes were constructed based on results from three independent experiments for each probe. Quantifications of bound and unbound probes were performed from densitometry analysis using phosphorimaging autoradiography. The fraction of probe bound to ZFP36L2 was calculated in regard to total amount (bound + unbound) of probe in each lane. Insets beside each panel correspond to the structural model obtained based on SHAPEMaP data, except for mARE 2197UU, which is based on the WT ARE2197 SHAPE-MaP model. Because of that, all nucleotides are represented in black and the mutated "U's" in green in this inset. Arrows in the insets indicate the start and end point of their respective probes. The nucleotides composing the functional ARE sequences are represented in larger fonts.

We performed a thorough dissection of the molecular basis of the ZFP36L2-ARE interaction, investigating the importance of the RNA secondary structure surrounding the ARE. To do this, we obtained SHAPE-MaP data from in vitro transcribed and refolded full-length mouse $(2531 \mathrm{bp})$ and human LHR (2534 bp) mRNAs. Our studies were performed with the chemical compound $1 \mathrm{M} 7$, which reacts equally with all four ribonucleotides (Merino et al. 2005; Siegfried et al. 2014). Using this approach, we could take advantage of the rigorously validated thermodynamic relationship between SHAPE reactivity and RNA folding energy (Tijerina et al. 2007; Cordero et al. 2012). Thus, because we have SHAPE reactivity data for over $98 \%$ of the nucleotides composing the LHR mRNA, our secondary structural model is fully informed by experimental data (Deigan et al. 2009), yielding a high confidence model. Our SHAPE-Map data revealed that mARE2197 and hARE2223 are present in hairpin loops
(Figs. 3, 6). Furthermore, the hairpin stem in mouse ARE2197 is more stable (high base-pairing probability, Fig. 9E) relative to the stem in hARE2223 (Fig. 9E); also, hARE2223 bound ZFP36L2 with a binding affinity 50-fold higher than did mARE2197 (Fig. 7D). Thus, although the two ARE-structures are similar, subtle differences in their thermodynamic stability appear to determine their affinity for ZFP36L2. Accordingly, we observed that RNA structural features surrounding the canonical nonamer sequence of the ARE are important in determining the affinity of the interaction. When the canonical nonamer sequence was tested in the context of mARE2197, the binding affinity to mZFP36L2 improved (Fig. 7B,D), but the affinity was still lower than the affinity of hARE2223 (Fig. 7C,D). Interestingly, when the two uracil residues of hARE2223 located outside the ARE were substituted by cytosines (Fig. 9C), stabilizing the hairpin stem, the protein-RNA interaction was dramatically 
A

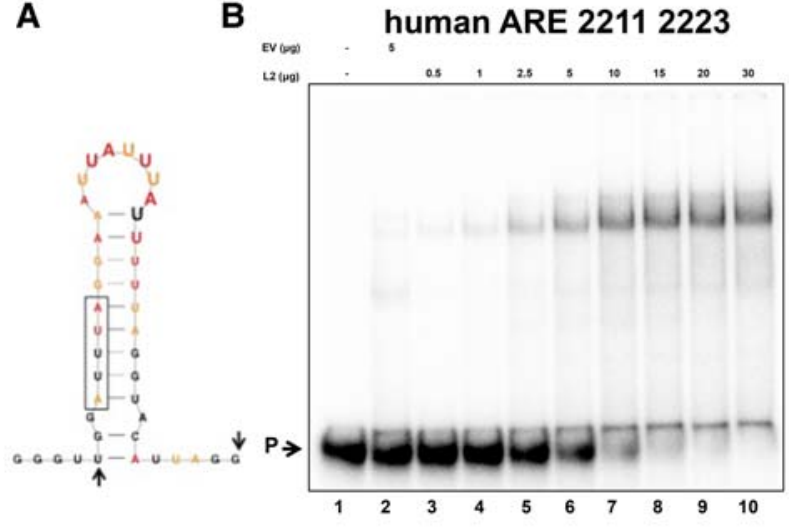

C

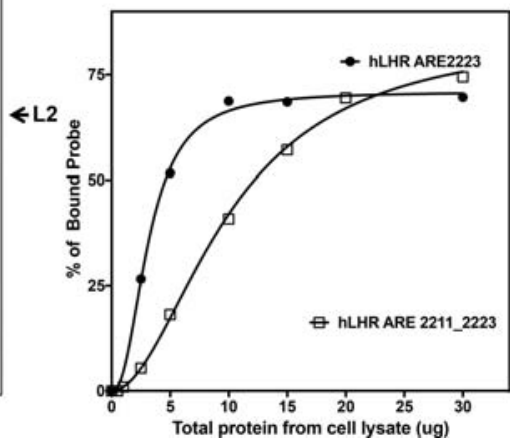

FIGURE 8. The RNA structural domain composing hARE2223 does not influence positively nonbinding hARE2211. (A) Structural model of the hARE2211_2223 probe based on SHAPE-MaP data. Arrows indicate the start and end point of the probe. (B) Increasing amounts of overexpressed mZFP36L2-HA were tested in a dose-dependent manner for the ability to shift the electrophoretic mobility of the hARE2211_2223 probe. Protein extracts were used in the following sequence: lane 1 , input probe incubated with buffer, no protein extract added; lane 2 contained $5 \mu \mathrm{g}$ of protein extract from HEK cells transfected with an empty vector; lanes 3-10 contained protein extract from HEK cells transfected with mZFP36L2-HA; with incremental amounts of protein as shown on the top of the gel. $(C)$ Curves of dose-response to mZFP36L2-HA for the hARE2211_2223 (open squares) or ARE2223 (black circles) probes were based on quantifications of bound and unbound probes.
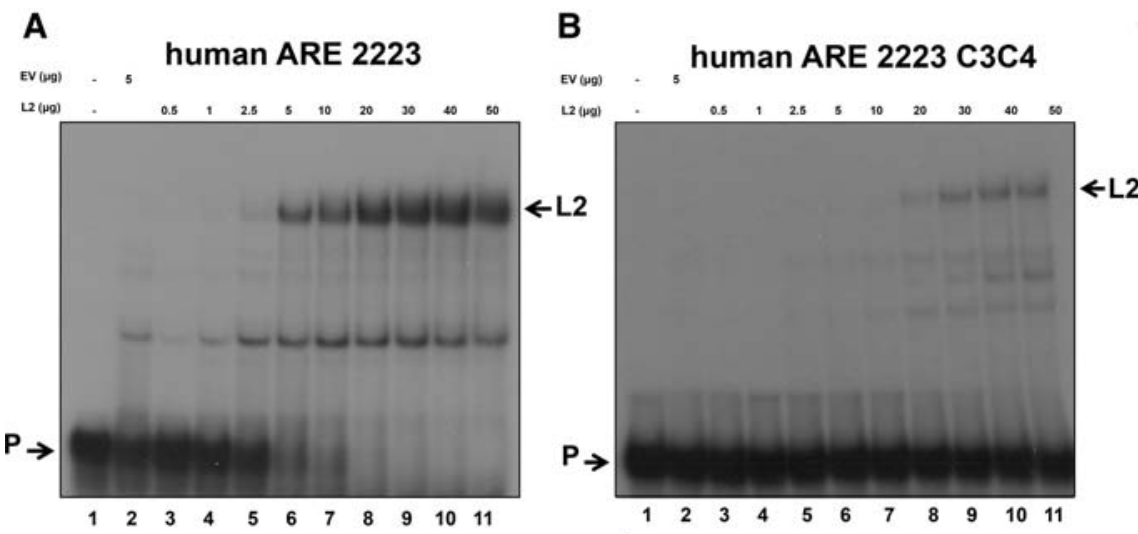

C
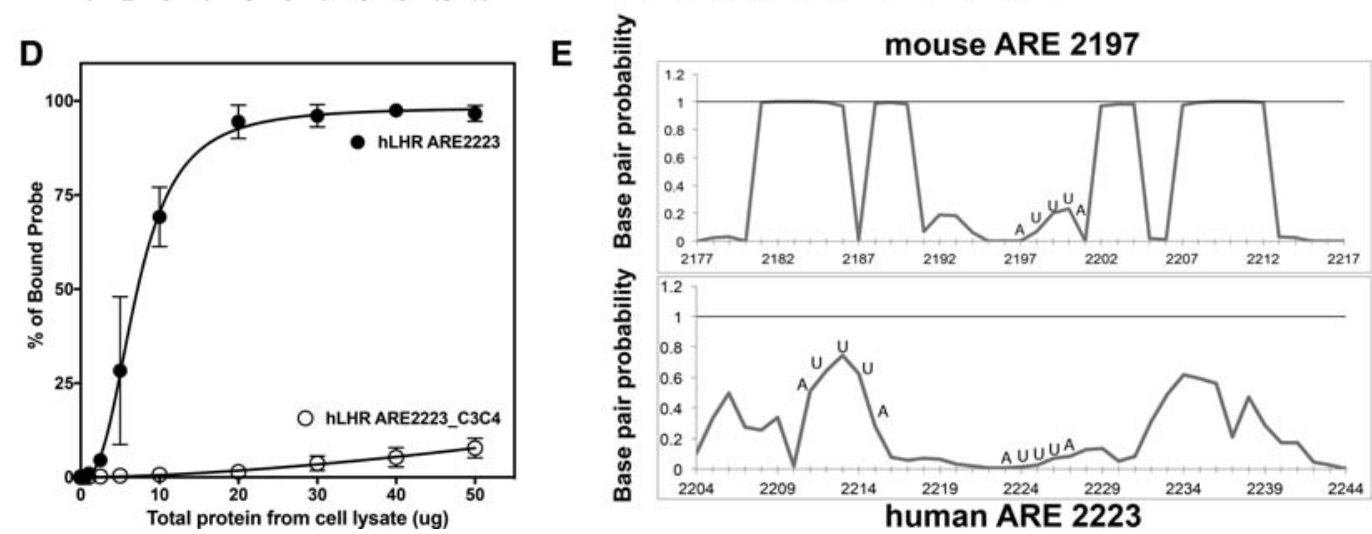

FIGURE 9. Dose response of WT and mutant C3C4 hARE2223 probes to mZFP36L2-HA. Increasing amounts of overexpressed mZFP36L2-HA were tested in a dose-dependent manner for the ability to shift the electrophoretic mobility of the WT hARE2223 $(A)$ and mutant hARE2223C3C4 (B) probes. In both gels, protein extracts were used in a similar sequence as described in Figure 7. (C) Structural model of human ARE2223C3C4 was based on the WT ARE2223 SHAPE-MaP data. Nucleotides corresponding to C3C4 were color coded in green. Arrows indicate the start and end point of the probe. $(D)$ Curves of dose-response to mZFP36L2 for the WT hARE 2223 and mutant hARE2223C3C4 probes were constructed based on the results from three independent experiments for each probe. Quantifications of bound and unbound probes were performed from densitometry analysis. (E) Ensemble base-pairing probabilities for each nucleotide in the vicinity of both of these AREs were calculated and plotted. A higher reactive score was found for the human ARE 2223 (lower panel). 
A

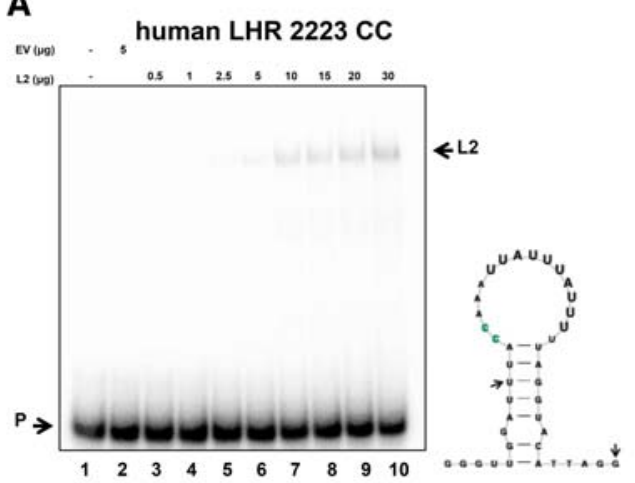

C human LHR 2223 CCG3G4

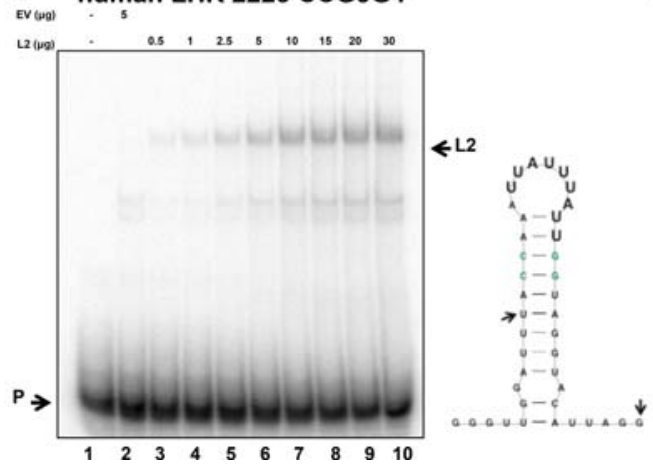

B

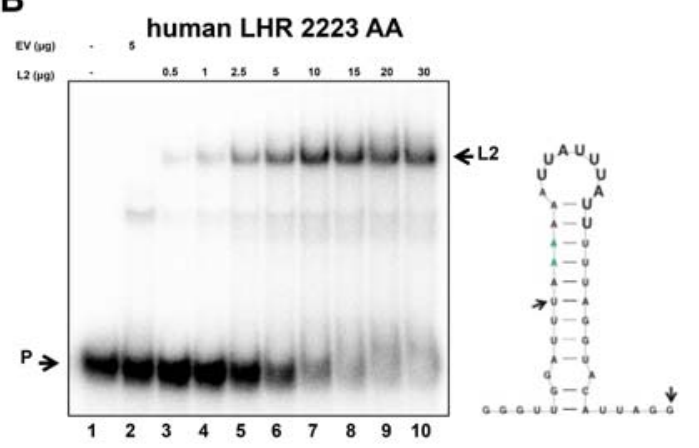

D

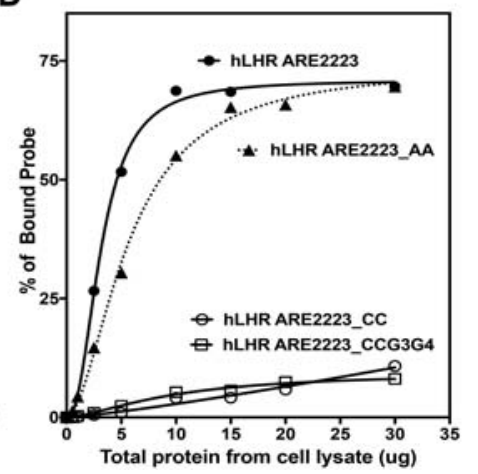

FIGURE 10. Mutant probes disrupting or preserving the stem, in the presence of U string of hARE2223, affect the binding affinity to mZFP36L2-HA. Increasing amounts of overexpressed mZFP36L2-HA were tested in a dose-dependent manner for the ability to shift the electrophoretic mobility of the mutant hARE2223CC $(A)$, hARE2223AA $(B)$, and the hARE2223CCG3G4 $(C)$ probes. In all three gels, protein extracts were used in a similar sequence as in Figure 8; lanes 3-10 contained protein extract from HEK cells transfected with mZFP36L2-HA; with incremental amounts of protein as shown on the top of the gel. Insets beside each panel correspond to the structural model obtained based on the WT ARE2223 SHAPE-MaP model; except for hARE2223CC, which is based on the predicted secondary structure model using RNAStructure. Accordingly, all nucleotides are represented in black, except the mutated nucleotides are shown in green. Arrows in the insets indicate the start and end point of their respective probes. The nucleotides composing the functional ARE sequences are represented in larger fonts. (D) Curves of dose-response to mZFP36L2-HA for the WT hARE2223 (black circles), hARE2223CC (open circles), hARE2223AA (black triangles), hARE2223CCG3G4 (open squares) probes were constructed based on quantifications of bound and unbound probes.

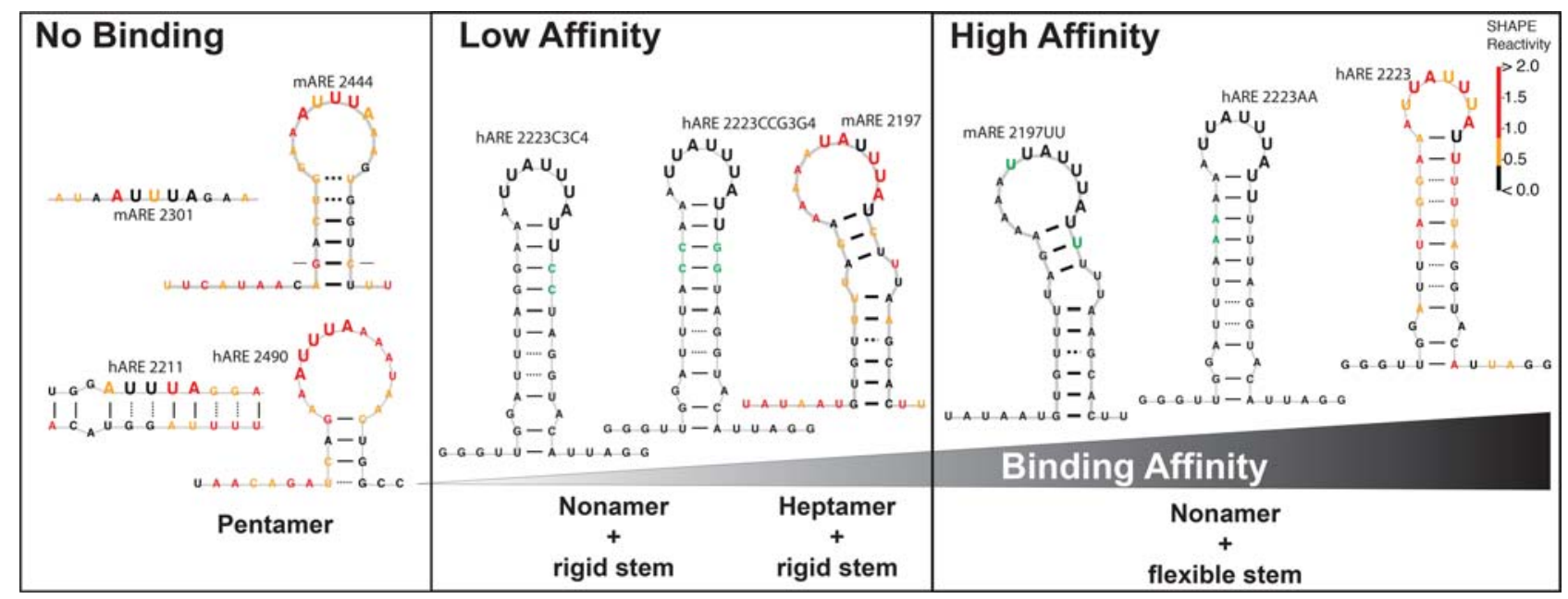

FIGURE 11. Summary of RNA secondary structures on the vicinity of each LHR-ARE sequence and corresponding binding affinity tested for ZFP36L2 interaction. RNA secondary structures derived from SHAPE-Map data are designed in color coded nucleotides according to their obtained reactivity value (see the SHAPE reactivity scale). The structures illustrated in black were created based on their corresponding WT structural model from SHAPE-MaP data; the mutant nucleotides are shown in green. 
reduced (Fig. 9B,D), despite the presence of the canonical UUAUUUAUU nonamer in this mutant. Further mutations preserving the string of $U$ residues in hARE2223, but altering the stem flexibility (Fig. 10A,B) confirmed our proposal. Nonetheless, we do not expect that RNA structural domains affect the affinity of all ARE-binding protein interactions. For example, Fialcowitz et al. (2005) noticed that a more rigid hairpin-like structure adopted by AREs from TNF mRNA strongly inhibited the interaction with the ARE-binding protein $\mathrm{p} 37^{\mathrm{AUF} 1}$, but not with $\mathrm{HuR}$, suggesting that HuR interaction with its RNA substrate is less dependent on the RNA structural conformation.

In the present study, we combined SHAPE data with biochemical experiments to dissect the interaction of ZFP36L2 with its target LHR mRNA. The results support our principal conclusion that RNA structure is relevant for the ZFP36L2LHR mRNA interaction at this specific ARE site. Based on the sequence comparison of human and mouse LHR mRNAs, the functional ARE was found to be conserved, despite the fact that these two species are estimated to have diverged over 100 million years ago (Nei et al. 2001). Interestingly, our RNA structural findings at the conserved ARE binding site suggests that this structural domain is an integral component of the interaction, and this structure has been conserved in mammals. A particularly salient feature of mammalian mRNA UTRs is their rapid evolutionary divergence when compared with coding sequences that are relatively more conserved. In the LHR transcript, two of the three AREs are conserved, but their positions and even their structural contexts are different. Nonetheless, hARE2223, which is homologous in position to mARE2197, also has a conserved structural context and a conserved function, i.e., binding to ZFP36L2.

It is unlikely that the observed difference in affinity, higher for hARE2223 than mARE2197 (Fig. 7), could be attributed to the ZFP36L2 protein. In fact, mouse and human ZFP36L2 proteins have barely diverged; they share $100 \%$ sequence identity in their tandem zinc finger domain, and as expected they displayed comparable binding affinity to hARE2223 (Fig. 5B,C).

As of now, few models of mRNA degradation seem to be influenced by RNA secondary structure. One example is the replication-dependent histone mRNAs that contain a conserved 3'-terminal stem-loop recognized by the stemloop binding protein (SLBP). SLBP recruits the factors that mediate the rapid degradation of histone mRNAs at the end of S phase (Marzluff et al. 2008). Another elegant model involves a 37-nt sequence that composes the constitutive decay element (CDE). This conserved stretch is present at the $3^{\prime}$ UTR of many immunity- and inflammation-related mRNAs (Stoecklin et al. 2003). The CDE folds into a stem-loop, which is the active conformation recognized by Roquin and Roquin2 proteins (Leppek et al. 2013). The conformational change triggered by this interaction recruits the Ccr4-Caf1Not deadenylase complex that initiates destabilization of tar- get mRNAs. Nonetheless, SLBP and Roquin are RNA-binding proteins that target stable stem-loop structures, while we are proposing that ZFP36L2 has a higher affinity for an ARE located in a flexible stem-loop, containing a double G-U wobble base-pairing, differing from a tightly basepaired stem-loop or a simple unstructured RNA. The role of structure in mRNA function has recently sparked much interest. Computational approaches suggest that structured mRNA motifs may be abundant (Parker et al. 2011; Goodarzi et al. 2012; McManus et al. 2015), but their actual existence and biological relevance need to be tested experimentally.

In conclusion, our multiple approach investigation strongly suggests that RNA structural flexibility is vital for protein recognition between ZFP36L2 and LHR mRNA targets, as summarized in Figure 11. The observed difference in flexibility between the mouse and human hairpins suggests that evolution is fine-tuning hairpin flexibility as a way to specifically regulate ZFP36L2 affinity. Thus, any small molecule able to modulate the RNA secondary structure of this RNA-protein interaction has the potential to regulate LHR mRNA stability. An exogenous molecule capable of modulating LHR mRNA degradation by changing the binding affinity of ZFP36L2 could constitute a provocative new way to control female fertility without the use of hormones.

\section{MATERIALS AND METHODS}

\section{Cell culture, transfections, and protein extracts}

HEK 293T cells (American Type Culture Collection) were maintained in Dulbecco's modified Eagle medium (DMEM) containing $10 \%$ fetal bovine serum, penicillin ( 100 units $/ \mathrm{mL}$ ), and streptomycin $(100 \mu \mathrm{g} / \mathrm{mL})$. One million HEK 293 cells were plated on a $100-\mathrm{mm}$ petri dish for transient transfections with vectors directing the expression of mZFP36L2-HA, mZFP36L2-GFP, or no product (empty vector; EV), using Lipofectamine 2000 (Invitrogen). The cells were incubated with the transfection mixture for $20 \mathrm{~h}$, after which the medium was replaced. Following $24 \mathrm{~h}$ of incubation in fresh medium, the cells were washed twice in cold phosphate-buffered saline, then gently scraped and incubated for $10 \mathrm{~min}$ in RIPA buffer solution containing $50 \mathrm{mM}$ Tris- $\mathrm{HCl}$ ( $\mathrm{pH} 8.3$ ), 5 mM EDTA, $0.15 \mathrm{M}$ $\mathrm{NaCl}, 1 \% \mathrm{NP}-40$, and protease inhibitor. Cytosolic protein extracts were obtained by collecting the supernatant fraction after centrifugation at $8944 \mathrm{~g}$ for $15 \mathrm{~min}$ at $4^{\circ} \mathrm{C}$. These lysates were used for electrophoretic mobility shift assays and immunoblotting. The total amount of protein was measured using a Bio-Rad assay.

\section{shRNA knockdown and mRNA decay assay}

MLTC1 cells were maintained in RPM1 1640 medium supplemented with $10 \%$ fetal bovine serum and penicillin (100 units $/ \mathrm{mL}$ ), and streptomycin $(100 \mu \mathrm{g} / \mathrm{mL})$. Cells were infected with a lentivirus vector containing a short hairpin RNA (shRNA) against ZFP36L2 (LV9), or with an empty vector (EV) as a negative control, as described in Zhang et al. (2013). MLTC-1 cells stably expressing either lentiviral vector were selected with puromycin $(10 \mu \mathrm{g} / \mathrm{mL})$ to assure 
that the viral particles were stably incorporated into the cellular genome and allowed to recover for $48 \mathrm{~h}$ in a puromycin-free medium prior to plating for RNA decay assays. The level of ZFP36L2 knockdown was assessed by immunoblotting on the same day of each RNA decay experiment. Knockdown (LV9) and control cells were pretreated with actinomycin $\mathrm{D}(4 \mu \mathrm{g} / \mathrm{mL})$ for $30 \mathrm{~min}$ before the time course initiation. Afterward, total RNA was isolated at $0,30,60,90$, and 120 min by TRIzol extraction (Ambion/Invitrogen). Samples were analyzed by qRT-PCR as described.

\section{Immunoblot analysis}

Protein samples were quantitated by Bradford assay (Bio-Rad). Ten micrograms of protein per lane was loaded on a $10 \%$ Tris-Glycine polyacrylamide gel and electrophoresed under denaturing conditions. The proteins were transferred from the gel to a nitrocellulose membrane using the Trans-Blot Turbo System (Bio-Rad). The membrane was blocked for 45 min with $5 \%$ nonfat milk (w/v) in a Tris-buffered saline solution containing $0.1 \%$ TWEEN (TBS-T). The following primary antibodies were used for protein detection: rabbit polyclonal anti-HA (1:10,000, Y-11, Santa Cruz), rabbit polyclonal anti- $\beta$-actin (1:5,000, N-21, Santa Cruz), and mouse monoclonal anti-GFP (1:10,000, JL8, Clontech). The HRP-conjugated secondary antibodies were either goat anti-mouse (1:10,000, Santa Cruz) or goat anti-rabbit (1:10,000, Bio-Rad), depending on the primary antibody used. The HRP signal was developed using the BioRad Western Clarity chemiluminescent substrate.

\section{RNA electrophoretic mobility shift assay}

Protein extracts were prepared from HEK 293T cells transfected with constructs driven by the CMV promoter followed by either mZFP36L2-HA or hZFP36L2-DDK, and empty vector. Protein extracts were incubated for $15 \mathrm{~min}$ at room temperature with $0.2 \times 10^{5}$ cpm of ${ }^{32} \mathrm{P}$-labeled RNA probe in a final volume of $26 \mu \mathrm{L}$ containing $10 \mathrm{mM}$ HEPES (pH 7.6), $40 \mathrm{mM} \mathrm{KCl,} 3 \mathrm{mM} \mathrm{MgCl}_{2}, 0.5 \mu \mathrm{g} / \mu \mathrm{L}$ heparin, and $1.2 \mu \mathrm{g}$ yeast tRNA, as previously described (Lai et al. 2000; Ball et al. 2014). The resultant reaction mixtures of protein-RNA complexes were then loaded onto $6 \%$ nondenaturing acrylamide (37.5:1) gels and subjected to electrophoresis at $150 \mathrm{~V}$ for $15 \mathrm{~min}$ followed by electrophoresis at $200 \mathrm{~V}$ for $90 \mathrm{~min}$ in $0.4 \times$ Trisborate/EDTA running buffer. The gel was dried, exposed to film (Carestream BIOMAX MR Film), and developed after $20 \mathrm{~h}$ of exposure. Dried gels were also exposed to a PhosphorImager screen and scanned using a Typhoon 8600 imager. ImageQuant software (GE Healthcare) was used to quantify the amount of bound and unbound probes for each EMSA. Values were normalized to blot the background for each experiment.

\section{Preparation of RNA probes}

The RNA probes were synthesized with the Riboprobe System-T7 (Promega) using synthetic DNA sequences immediately down- stream from a T7 promoter, as previously described (Milligan et al. 1987). The RNA probes were body-labeled during the transcription process, which was performed in the presence of $\left[\alpha^{-}{ }^{32} \mathrm{P}\right]$ UTP (3000 Ci/mmol; PerkinElmer). The synthesized RNA probes were separated from the free nucleotides using Sephadex G25 columns (GE Healthcare Life Sciences) and subsequently electrophoresed on a $16 \%$ polyacrylamide urea gel. The probes were purified from excised gel fragments after detection by autoradiography, as previously described (Ball et al. 2014). The amount of RNA used in each lane of the EMSA was calculated to be $\sim 10$ femtomoles. The new mouse probes differ slightly; specifically for ARE2197 it starts and ends $3 \mathrm{nt}$ earlier than the one previously published (Ball et al. 2014). A list of the RNA probe sequences used and their respective ID names are provided in Table 1.

\section{Reverse transcriptase (RT)-PCR and real-time RT-PCR}

The High Capacity cDNA Reverse Transcription Kit (Applied Biosystems) was used according to the manufacturer's instructions to synthesize first strand cDNA from $1 \mu \mathrm{g}$ of total RNA isolated from MLTC-1 cells. To quantify ZFP36L2 and LHR mRNAs, 100 ng of first strand cDNA was combined with predesigned primer/ probe sets and TaqMan Universal PCR Master Mix (Applied Biosystems). For a housekeeping gene reference, $8 \mathrm{ng}$ of first strand cDNA was used to quantify GAPDH. All reactions were performed in triplicate in 96-well plates. Assays were run on the $7900 \mathrm{HT}$ sequence detector system (Applied Biosystems). The relative abundance of each gene was determined by the $\Delta \mathrm{Ct}$ method using GAPDH as reference.

\section{SHAPE-MaP}

For the mouse LHR mRNA, its cDNA template was amplified from the plasmid pcDNA3.1-mLHR using the primers CMV-For and pcDNA-Rev2 (5'-CGCAAATGGGCGGTAGGCGTG-3', $\quad 5^{\prime}$ GGCTGATCAGCGAGCTCTAGCATT-3', respectively). This PCR product, containing a $\mathrm{T} 7$ promoter at the $5^{\prime}$ end, was transcribed using a HiScribe T7 High Yield RNA Synthesis Kit (New England Biolabs), and the RNA was purified using an Ambion MEGAClear 
Transcription Clean-up Kit (Thermo Fisher). For the human LHR mRNA, a T7 promoter was introduced to the $5^{\prime}$ end of the plasmid pUC57-hLHCGR during PCR amplification using the primers T7FwhLHR and RevhLHR (5'-TAATACGACTCACTATAGGGTT CGCCGGCCATGAAGC-3 and 5'-TTAGCCACATGTGGCTAGT GGC-3', respectively). This PCR product was used for a transcription reaction with a T7 RNA synthesis kit followed by a cleanup step, as mentioned above. A minimum of 2 pmol of RNA was used for each modification reaction as described previously (Siegfried et al. 2014) with some modifications. Briefly, RNA was diluted in water, denatured at $95^{\circ} \mathrm{C}$ for $1 \mathrm{~min}$, and snap-cooled on ice. After the addition of folding buffer $\left(100 \mathrm{mM} \mathrm{KCl}, 10 \mathrm{mM} \mathrm{MgCl}_{2}\right.$, $100 \mathrm{mM}$ HEPES, $\mathrm{pH} 8.0$ final concentration), the RNA was folded at $37^{\circ} \mathrm{C}$ for $10-15 \mathrm{~min}$. The $45 \mu \mathrm{L}$ of folded RNA was either mixed with $5 \mu \mathrm{L}$ DMSO (negative control) or $2 \mu \mathrm{L}$ DMSO $+1 \mu \mathrm{L} 500 \mathrm{mM}$ 1-methyl-7-nitroisatoic anhydride (1M7) in DMSO (modified sample). In $1.5 \mathrm{~min}$ intervals, two additional $1 \mu \mathrm{L}$ aliquots of $500 \mathrm{mM}$ of $1 \mathrm{M} 7$ were added to the modified sample to maximize the level of modification. After $5 \mathrm{~min}$, reactions were desalted using G25 or G50 columns. A third sample of the RNA (denatured control) was conducted in parallel in which the RNA was diluted into $50 \mathrm{mM}$ HEPES pH 8.0, $4 \mathrm{mM}$ EDTA, 50\% formamide and heated to $95^{\circ}$ C. This RNA sample was modified at $95^{\circ} \mathrm{C}$ three times with $1 \mu \mathrm{L}$ of $500 \mathrm{mM}$ of $1 \mathrm{M} 7$ in DMSO added 5-6 sec apart. Thus, our data collection uses two negative controls: chemical modifications found when only the solvent (DMSO) was added to the transcript; and a second condition where the RNA is fully denatured by the combined action of formamide and high temperature (Siegfried et al. 2014). After $1 \mathrm{~min}$, reactions were desalted using G25 or G50 columns. The RNA was reverse transcribed using SuperScript II (Life Technologies) with random nonamers as previously described (Siegfried et al. 2014), followed by cleanup with a G25 or G50 column. The second strand was synthesized using the NEBNext mRNA Second Strand Synthesis Module (New England Biolabs). The double-stranded DNA was then prepared using a Nextera or Nextera XT DNA Library Prep Kit (Illumina). Following concentration determination via Qubit and library analysis using a Bioanalyzer, libraries were run on a miSeq (Illumina), and the resulting data were analyzed using the ShapeMapper pipeline (Rocca-Serra et al. 2011; Siegfried et al. 2014).

\section{SUPPLEMENTAL MATERIAL}

Supplemental material is available for this article.

\section{ACKNOWLEDGMENTS}

We greatly appreciate Dr. William Marzluff for his encouragement, continuous support, and unique ability of congregating a rich scientific environment for extensive discussions and helpful comments. We thank Dr. Shawn Lyons for sharing his calculation tool to estimate the amount of labeled probe using in vitro transcription. This work was supported by the National Institutes of Health (NIH), National Institute of Child Health and Human Development grant K08 HD069597 to S.B.V.R.; Institute for Biological Recognition and Catalysis, Inc. to S.B.V.R.; UNC TraCS grant no. 550KR11128 to S.B.V.R.; as well as NIH grants NHLBI R01 HL111527 (National Heart, Lung, and Blood Institute), NIGMS R01 GM101237 (National Institute of General Medical
Sciences), and NHGRI HG008133 (National Human Genome Research Institute) to A.L. R.M.M. was partially supported by a National Institutes of Health training grant awarded to the Curriculum in Genetics and Molecular Biology (5T32GM007092).

Received December 19, 2016; accepted April 16, 2017.

\section{REFERENCES}

Ascoli M, Fanelli F, Segaloff DL. 2002. The lutropin/choriogonadotropin receptor, a 2002 perspective. Endocr Rev 23: 141-174.

Bakheet T, Frevel M, Williams BR, Greer W, Khabar KS. 2001. ARED: human AU-rich element-containing mRNA database reveals an unexpectedly diverse functional repertoire of encoded proteins. Nucleic Acids Res 29: 246-254.

Ball CB, Rodriguez KF, Stumpo DJ, Ribeiro-Neto F, Korach KS, Blackshear PJ, Birnbaumer L, Ramos SB. 2014. The RNA-binding protein, ZFP36L2, influences ovulation and oocyte maturation. PLoS One 9: e97324.

Bellaousov S, Reuter JS, Seetin MG, Mathews DH. 2013. RNAstructure: web servers for RNA secondary structure prediction and analysis. Nucleic Acids Res 41: W471-W474.

Blackshear PJ. 2002. Tristetraprolin and other CCCH tandem zinc-finger proteins in the regulation of mRNA turnover. Biochem Soc Trans 30: 945-952.

Blackshear PJ, Lai WS, Kennington EA, Brewer G, Wilson GM, Guan X, Zhou P. 2003. Characteristics of the interaction of a synthetic human tristetraprolin tandem zinc finger peptide with AU-rich elementcontaining RNA substrates. J Biol Chem 278: 19947-19955.

Brewer BY, Malicka J, Blackshear PJ, Wilson GM. 2004. RNA sequence elements required for high affinity binding by the zinc finger domain of tristetraprolin: conformational changes coupled to the bipartite nature of Au-rich mRNA-destabilizing motifs. J Biol Chem 279: 27870-27877.

Bukovský A, Chen TT, Wimalasena J, Caudle MR. 1993. Cellular localization of luteinizing hormone receptor immunoreactivity in the ovaries of immature, gonadotropin-primed and normal cycling rats. Biol Reprod 48: 1367-1382.

Cordero P, Kladwang W, VanLang CC, Das R. 2012. Quantitative dimethyl sulfate mapping for automated RNA secondary structure inference. Biochemistry 51: 7037-7039.

Deigan KE, Li TW, Mathews DH, Weeks KM. 2009. Accurate SHAPEdirected RNA structure determination. Proc Natl Acad Sci 106: 97-102.

Del Campo C, Bartholomäus A, Fedyunin I, Ignatova Z. 2015. Secondary structure across the bacterial transcriptome reveals versatile roles in mRNA regulation and function. PLoS Genet 11: e1005613.

Ding Y, Tang Y, Kwok CK, Zhang Y, Bevilacqua PC, Assmann SM. 2014. In vivo genome-wide profiling of RNA secondary structure reveals novel regulatory features. Nature 505: 696-700.

Fialcowitz EJ, Brewer BY, Keenan BP, Wilson GM. 2005. A hairpin-like structure within an AU-rich mRNA-destabilizing element regulates trans-factor binding selectivity and mRNA decay kinetics. J Biol Chem 280: 22406-22417.

Goodarzi H, Najafabadi HS, Oikonomou P, Greco TM, Fish L, Salavati R, Cristea IM, Tavazoie S. 2012. Systematic discovery of structural elements governing stability of mammalian messenger RNAs. Nature 485: 264-268.

Hofacker IL, Stadler PF. 2006. Memory efficient folding algorithms for circular RNA secondary structures. Bioinformatics 22: 1172-1176.

Hoffman YM, Peegel H, Sprock MJ, Zhang QY, Menon KM. 1991. Evidence that human chorionic gonadotropin/luteinizing hormone receptor down-regulation involves decreased levels of receptor messenger ribonucleic acid. Endocrinology 128: 388-393.

Incarnato D, Neri F, Anselmi F, Oliviero S. 2014. Genome-wide profiling of mouse RNA secondary structures reveals key features of the mammalian transcriptome. Genome Biol 15: 491. 
Kash JC, Menon KM. 1998. Identification of a hormonally regulated luteinizing hormone/human chorionic gonadotropin receptor mRNA binding protein. Increased mRNA binding during receptor downregulation. J Biol Chem 273: 10658-10664.

Kash JC, Menon KM. 1999. Sequence-specific binding of a hormonally regulated mRNA binding protein to cytidine-rich sequences in the lutropin receptor open reading frame. Biochemistry 38: 1688916897.

Kertesz M, Wan Y, Mazor E, Rinn JL, Nutter RC, Chang HY, Segal E. 2010. Genome-wide measurement of RNA secondary structure in yeast. Nature 467: 103-107.

Lai WS, Carballo E, Thorn JM, Kennington EA, Blackshear PJ. 2000. Interactions of $\mathrm{CCCH}$ zinc finger proteins with mRNA. Binding of tristetraprolin-related zinc finger proteins to Au-rich elements and destabilization of mRNA. J Biol Chem 275: 17827-17837.

Lai WS, Carrick DM, Blackshear PJ. 2005. Influence of nonameric AUrich tristetraprolin-binding sites on mRNA deadenylation and turnover. J Biol Chem 280: 34365-34377.

LaPolt PS, Oikawa M, Jia XC, Dargan C, Hsueh AJ. 1990. Gonadotropin-induced up- and down-regulation of rat ovarian $\mathrm{LH}$ receptor message levels during follicular growth, ovulation and luteinization. Endocrinology 126: 3277-3279.

Lavender CA, Lorenz R, Zhang G, Tamayo R, Hofacker IL, Weeks KM. 2015. Model-free RNA sequence and structure alignment informed by SHAPE probing reveals a conserved alternate secondary structure for 16S rRNA. PLoS Comput Biol 11: e1004126.

Lei ZM, Rao CV, Kornyei JL, Licht P, Hiatt ES. 1993. Novel expression of human chorionic gonadotropin/luteinizing hormone receptor gene in brain. Endocrinology 132: 2262-2270.

Leppek K, Schott J, Reitter S, Poetz F, Hammond MC, Stoecklin G. 2013. Roquin promotes constitutive mRNA decay via a conserved class of stem-loop recognition motifs. Cell 153: 869-881.

Lu DL, Peegel H, Mosier SM, Menon KM. 1993. Loss of lutropin/human choriogonadotropin receptor messenger ribonucleic acid during ligand-induced down-regulation occurs post transcriptionally. Endocrinology 132: 235-240.

Maclean KN, McKay IA, Bustin SA. 1998. Differential effects of sodium butyrate on the transcription of the human TIS11 family of early-response genes in colorectal cancer cells. Br J Biomed Sci 55: 184-191.

Marzluff WF, Wagner EJ, Duronio RJ. 2008. Metabolism and regulation of canonical histone mRNAs: life without a poly(A) tail. Nat Rev Genet 9: 843-854.

McManus J, Cheng Z, Vogel C. 2015. Next-generation analysis of gene expression regulation-comparing the roles of synthesis and degradation. Mol Biosyst 11: 2680-2689.

Menon KM, Menon B. 2014. Regulation of luteinizing hormone receptor expression by an RNA binding protein: role of ERK signaling. Indian J Med Res 140(Suppl): S112-S119.

Menon B, Sinden J, Menon KM. 2013. Association of luteinizing hormone receptor (LHR) mRNA with its binding protein leads to decapping and degradation of the mRNA in the p bodies. Biochim Biophys Acta 1833: 1173-1179.

Merino EJ, Wilkinson KA, Coughlan JL, Weeks KM. 2005. RNA structure analysis at single nucleotide resolution by selective $2^{\prime}$-hydroxyl acylation and primer extension (SHAPE). J Am Chem Soc 127: 4223-4231.

Milligan JF, Groebe DR, Witherell GW, Uhlenbeck OC. 1987. Oligoribonucleotide synthesis using T7 RNA polymerase and synthetic DNA templates. Nucleic Acids Res 15: 8783-8798.
Nei M, Xu P, Glazko G. 2001. Estimation of divergence times from multiprotein sequences for a few mammalian species and several distantly related organisms. Proc Natl Acad Sci 98: 2497-2502.

Nie XF, Maclean KN, Kumar V, McKay IA, Bustin SA. 1995. ERF-2, the human homologue of the murine Tis11d early response gene. Gene 152: 285-286.

Parker BJ, Moltke I, Roth A, Washietl S, Wen J, Kellis M, Breaker R, Pedersen JS. 2011. New families of human regulatory RNA structures identified by comparative analysis of vertebrate genomes. Genome Res 21: 1929-1943.

Ramos SB. 2012. Characterization of $\Delta \mathrm{N}-\mathrm{Zfp} 3612$ mutant associated with arrest of early embryonic development and female infertility. J Biol Chem 287: 13116-13127.

Ramos SB, Stumpo DJ, Kennington EA, Phillips RS, Bock CB, RibeiroNeto F, Blackshear PJ. 2004. The CCCH tandem zinc-finger protein Zfp3612 is crucial for female fertility and early embryonic development. Development 131: 4883-4893.

Rocca-Serra P, Bellaousov S, Birmingham A, Chen C, Cordero P, Das R, Davis-Neulander L, Duncan CD, Halvorsen M, Knight R, et al. 2011. Sharing and archiving nucleic acid structure mapping data. RNA 17: 1204-1212.

Rouskin S, Zubradt M, Washietl S, Kellis M, Weissman JS. 2014 Genome-wide probing of RNA structure reveals active unfolding of mRNA structures in vivo. Nature 505: 701-705.

Siegfried NA, Busan S, Rice GM, Nelson JA, Weeks KM. 2014. RNA motif discovery by SHAPE and mutational profiling (SHAPE-MaP). Nat Methods 11: 959-965.

Soldatov RA, Vinogradova SV, Mironov AA. 2014. RNASurface: fast and accurate detection of locally optimal potentially structured RNA segments. Bioinformatics 30: 457-463.

Stoecklin G, Lu M, Rattenbacher B, Moroni C. 2003. A constitutive decay element promotes tumor necrosis factor alpha mRNA degradation via an AU-rich element-independent pathway. Mol Cell Biol 23: 3506-3515.

Tijerina P, Mohr S, Russell R. 2007. DMS footprinting of structured RNAs and RNA-protein complexes. Nat Protoc 2: 2608-2623.

Varnum BC, Ma QF, Chi TH, Fletcher B, Herschman HR. 1991. The TIS11 primary response gene is a member of a gene family that encodes proteins with a highly conserved sequence containing an unusual Cys-His repeat. Mol Cell Biol 11: 1754-1758.

Wan Y, Qu K, Zhang QC, Flynn RA, Manor O, Ouyang Z, Zhang J, Spitale RC, Snyder MP, Segal E, et al. 2014. Landscape and variation of RNA secondary structure across the human transcriptome. Nature 505: 706-709.

Worthington MT, Pelo JW, Sachedina MA, Applegate JL, Arseneau KO, Pizarro TT. 2002. RNA binding properties of the AU-rich elementbinding recombinant Nup475/TIS11/tristetraprolin protein. J Biol Chem 277: 48558-48564.

Xu N, Chen CY, Shyu AB. 1997. Modulation of the fate of cytoplasmic mRNA by AU-rich elements: key sequence features controlling mRNA deadenylation and decay. Mol Cell Biol 17: 4611-4621.

Zeleznik AJ. 2004. The physiology of follicle selection. Reprod Biol Endocrinol 2: 31.

Zhang M, Shi H, Segaloff DL, Van Voorhis BJ. 2001. Expression and localization of luteinizing hormone receptor in the female mouse reproductive tract. Biol Reprod 64: 179-187.

Zhang L, Prak L, Rayon-Estrada V, Thiru P, Flygare J, Lim B, Lodish HF. 2013. ZFP36L2 is required for self-renewal of early burst-forming unit erythroid progenitors. Nature 499: 92-96. 

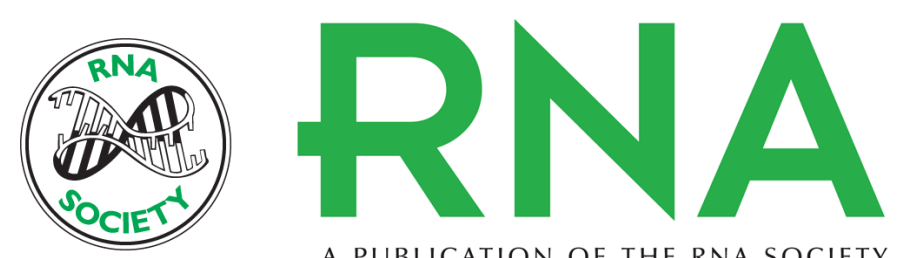

A PUBLICATION OF THE RNA SOCIETY

\section{Impact of RNA structure on ZFP36L2 interaction with luteinizing hormone receptor $\mathrm{mRNA}$}

Christopher B. Ball, Amanda C. Solem, Rita M. Meganck, et al.

RNA 2017 23: 1209-1223 originally published online April 28, 2017

Access the most recent version at doi:10.1261/rna.060467.116

\section{Supplemental http://rnajournal.cshlp.org/content/suppl/2017/04/28/rna.060467.116.DC1 Material}

References This article cites 52 articles, 17 of which can be accessed free at: http://rnajournal.cshlp.org/content/23/8/1209.full.html\#ref-list-1

Creative This article is distributed exclusively by the RNA Society for the first 12 months after the Commons License full-issue publication date (see http://rnajournal.cshlp.org/site/misc/terms.xhtml). After 12 months, it is available under a Creative Commons License (Attribution-NonCommercial 4.0 International), as described at http://creativecommons.org/licenses/by-nc/4.0/.
Email Alerting Receive free email alerts when new articles cite this article - sign up in the box at the Service top right corner of the article or click here.

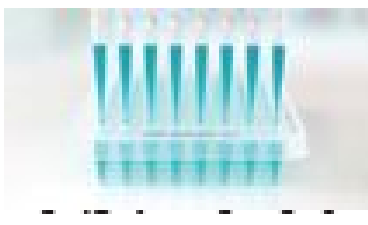

\section{Providing Precise Solutions for} your research.

To subscribe to $R N A$ go to:

http://rnajournal.cshlp.org/subscriptions 